\title{
Analysis of Convective Thunderstorm Split Cells in South-Eastern Romania
}

\author{
Daniel Carbunaru, ${ }^{1,2}$ Sabina Stefan, ${ }^{1}$ Monica Sasu, ${ }^{1,2}$ and Victor Stefanescu ${ }^{1,2}$ \\ ${ }^{1}$ Department of Atmospheric Physics, Faculty of Physics, University of Bucharest, P.O. Box MG-11, 077125 Bucharest, Romania \\ ${ }^{2}$ National Meteorological Administration, Bucuresti-Ploiesti Avenue, No. 97, 013686 Bucharest, Romania \\ Correspondence should be addressed to Daniel Carbunaru; daniel.carbunaru@meteoromania.ro
}

Received 29 August 2012; Revised 21 November 2012; Accepted 22 November 2012

Academic Editor: Helena A. Flocas

Copyright (C) 2013 Daniel Carbunaru et al. This is an open access article distributed under the Creative Commons Attribution License, which permits unrestricted use, distribution, and reproduction in any medium, provided the original work is properly cited.

\begin{abstract}
The mesoscale configurations are analysed associated withthe splitting process of convective cells responsible for severe weather phenomena in the south-eastern part of Romania. The analysis was performed using products from the S-band Doppler weather radar located in Medgidia. The cases studied were chosen to cover various synoptic configurations when the cell splitting process occurs. To detect the presence and intensity of the tropospheric jet, the Doppler velocity field and vertical wind profiles derived from radar algorithms were used. The relative Doppler velocity field was used to study relative flow associated with convective cells. Trajectories and rotational characteristics associated with convective cells were obtained from reflectivity and relative Doppler velocity fields at various elevations. This analysis highlights the main dynamic features associated with the splitting process of convective cells: the tropospheric jet and vertical moisture flow associated with the configuration of the flow relative to the convective cells for the lower and upper tropospheric layers. These dynamic characteristics seen in the Doppler based velocity field and in the relative Doppler velocity field to the storm can indicate further evolution of convective developments, with direct implications to very short range forecast (nowcasting).
\end{abstract}

\section{Introduction}

In south-eastern Romania, in the convective season (from May to September), severe weather phenomena develop frequently and evolve [1-5], sometimes leading to significant damages. Analysis of severe convective events and their structure, at least for certain classes of phenomena (isolated convective cells), taking into account the mesoscale configuration can improve the nowcasting procedures. Using an S-band Doppler radar (10 cm wavelength), we see that the mesoscale phenomena (supercellular thunderstorms) have certain features during their dynamic evolution. Of great importance in understanding the evolution of supercells is the splitting process (separation of the convective cells in two other ones rotating opposite to one another, namely, cyclonic and anticyclonic), a process that takes place during the evolution of convective developments and is closely linked to the state of mesoscale dynamic configuration, especially vertical wind shear $[6,7]$. This process has been studied both qualitatively [8-18] and by numeric analysis [19-21], highlighting the interaction between horizontal vorticity from the vertical profile of horizontal wind and the updraft.

Depending on the curvature of the hodograph, the development of convective cells is favoured when the propagation is either to the right, or to the left oftroposphericshear; both cells may be favoured as well, when the hodograph is linear. Along with this particular interaction, there may also exist secondary ones [22] that lead to the diminishing of the cell that propagates to the left of shear vector, in the Northern Hemisphere. Observations of the split process when the Doppler radar is used [23-32] highlight the cyclonic and anticyclonic rotation, within the field of Doppler velocity, associated with convective cells compatible with vertical shear.

The above studies also showed the asymmetry between the cells that propagate to the right and those that propagate 


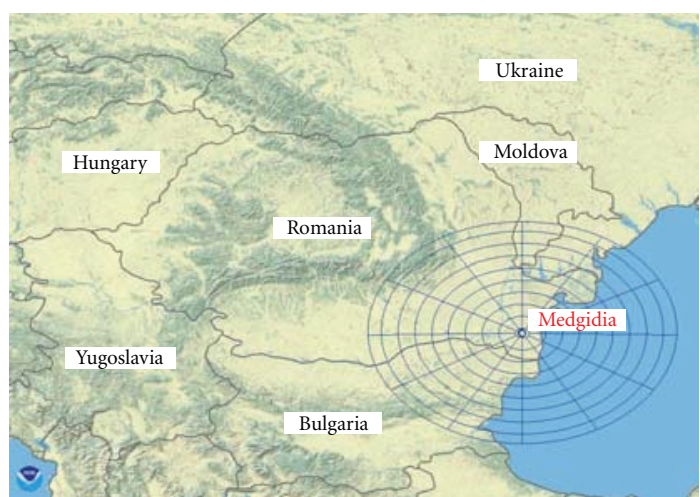

FIGURE 1: The spatial domain of radar analysis (geographic projection). The radar range is $230 \mathrm{~km}$, the spatial resolution is $1 \mathrm{~km}$, and the temporal resolution is 6 minutes, between two scans. NOAA Weather and Climate Toolkit (http://www.ncdc.noaa.gov/oa/wct/).

to the left of the tropospheric shear vector in the Northern Hemisphere, the latter generally has a shorter lifespan than the former, but is associated with severe hail.

In some cases the inflow at low levels and the outflow at upper levels [33] to and from the storm were seen with the aid of the Doppler relative velocity field; these two flows are in direct correlation with the intensity of updraft.

In this paper, several cases are analysed which featured the splitting process of strongly convective cells (supercells). The basic criteria in choosing these cases are the different mesoscale configuration (various directions of the tropospheric flow). The study focused on the analysis from fields and products of the meteorological Doppler radar that can provide relevant data on the severity of convective phenomena.

This paper is structured as follows. The first part contains the radar data that were used during the analysis of splitting processes, and the methodology thereof. At the second part, several case studies are presented that emphasize certain characteristics of the mentioned process. The paper ends with conclusions derived from these case studies, namely, mesoscale dynamic features and some particularities of convective cells trajectories. Since most of the convective cells appearing in the radar fields featured supercell traits, the common elements that were identified could be used in nowcasting.

\section{Data and Methods}

For the dynamic mesoscale analysis and that of the splitting process, the WSR-98D Doppler radar in $S$ band $(10 \mathrm{~cm})$ was used, located in Medgidia (south-eastern Romania) (Figure $1)$. The range of the radar is shown in Figure 1.

The splitting process was analyzed in the fields of radar reflectivity, Doppler base velocity, and that of Doppler relative velocity at different scan elevations, in order to see the formation of cyclonic and anticyclonic vortices. The Doppler relative velocity field is obtained from the Doppler base velocity field minus the average velocity of all detected storms and represents Doppler velocity field of the reference storm [34]. The Principal Users Processor (PUP) software (METSTAR WSR-98D PUP version 10.8.R) was used. The study of Doppler velocity field at various elevations, in parallel with the Vertical Azimuth Display (VAD) Wind Velocity product resulted in information about the vertical shear of horizontal velocities and tropospheric jets. The VAD Wind Velocity is a Doppler weather radar product which gives the vertical profile of horizontal wind vectors above radar station [34-36]. Strong shear in the wind field assumes the existence of tropospheric low-level jet (LLJ) or upperlevel jet (ULJ). Also the Doppler relative velocity field gave information about the low and upper relative flow associated to the storms in radar field. The presence of relative lowlevel flow was analysed (arrow-shaped tube, in the lower part of Figures 2(a) and 2(b)) and the relative upper-level flow (arrow-shaped tube, at top of Figures 2(a) and 2(b)). For the first three analysed cases, vertical vorticity profiles were made, further to be compared with circular movement associated with supercells (horizontal circles with cyclonic and anticyclonic vorticity, in Figure 2).

The evolution of convective cells was observed in the reflectivity field at elevations of 0.5 and 1.5 degrees, also in the Doppler radial velocities field and in the Doppler relative velocity field at elevations of $0.5,1.5,2.4$, and 3.4 degrees.

The evolution in time and space of each convective cell that was characterised by the splitting process was also observed. Identification of splitting was done by tracking both reflectivity and cyclonic or anticyclone rotation, as seen in Figures 3(a) and 3(b). Figure 3(c) shows how the vertical vorticity of rotational movements was calculated.

Thus, for each rotational motion, maximum inbound and outbound velocities were identified in the Doppler relative velocity field at elevation where rotational movement had maximum intensity. The PUP application was used. For the actual calculation, radar algorithm is dividing the difference between the maximum inbound velocity and the maximum outbound velocity, by the distance between the two (mesocyclone diameter in Figure 3(c)).

Trajectories of convective cells in each case were obtained using polar coordinates, relative to the radar position, of the cells before and after the splitting. For the three cases studied in detail, the result was a map showing the individual characteristics of convective developments, taking into account the stage before splitting and the after-splitting stage (which is associated with the cyclonic and anticyclone rotation). Vertical variation of the horizontal velocity (vertical shear) was derived from the VAD Wind Profile algorithm and vertical profiles were then constructed from wind shear at particular moments, representative of the evolution of vertical shear during the life of the convective cell. The vertical domain associated with the $z$-coordinate was separated into a domain with directional shear (in the lower tropospheric layer) and a domain with nondirectional shear (in the middle tropospheric level). This division was possible because the dynamic configuration near the radar site, at least in the three cases studied, has a nondirectional shear above $1800 \mathrm{~m}$ associated with an ULJ, and directional shear below $1800 \mathrm{~m}$. 


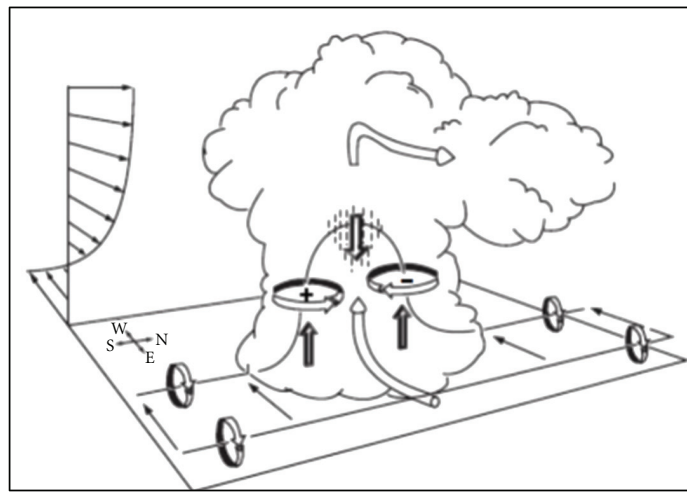

(a)

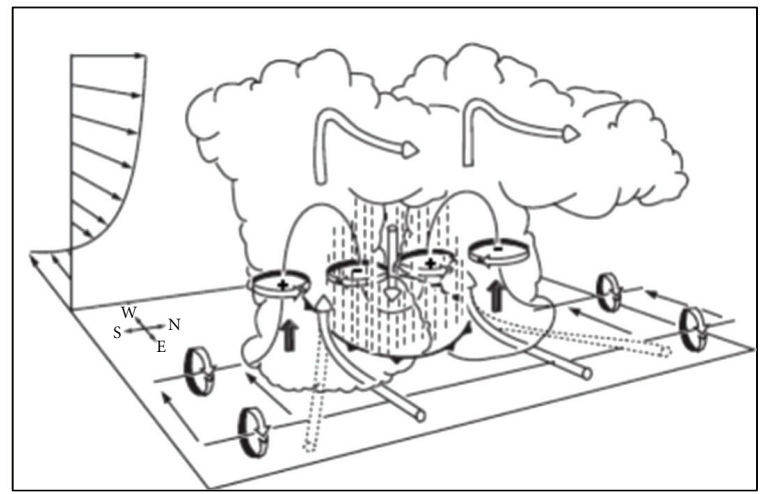

(b)

FIGURE 2: Tiling of the horizontal vorticity due to updraft (a). Negative vorticity maxima (on the left of shear) and positive vorticity maxima (on the right of shear) and (b) the convective cell split in two other cells with opposite vorticity (from Lin 2007, adapted by Klemp 1987, and from Rotuno 1981).

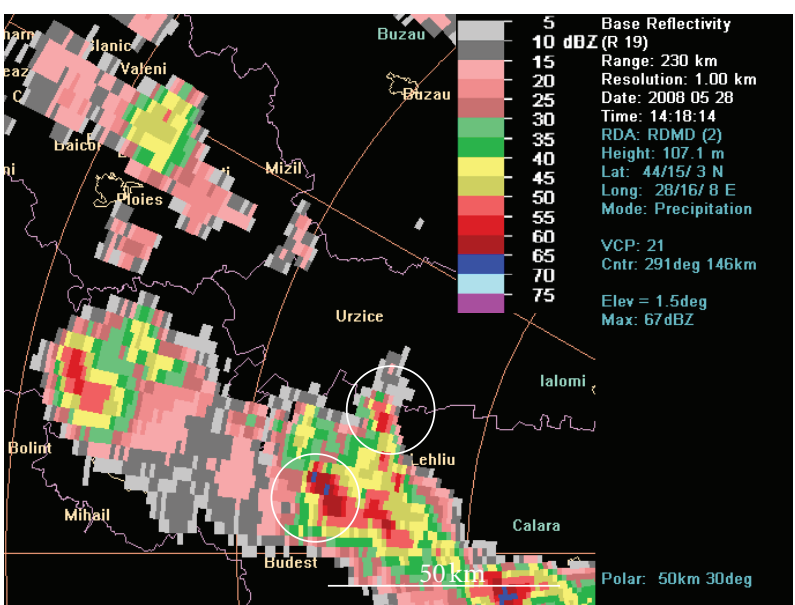

(a)

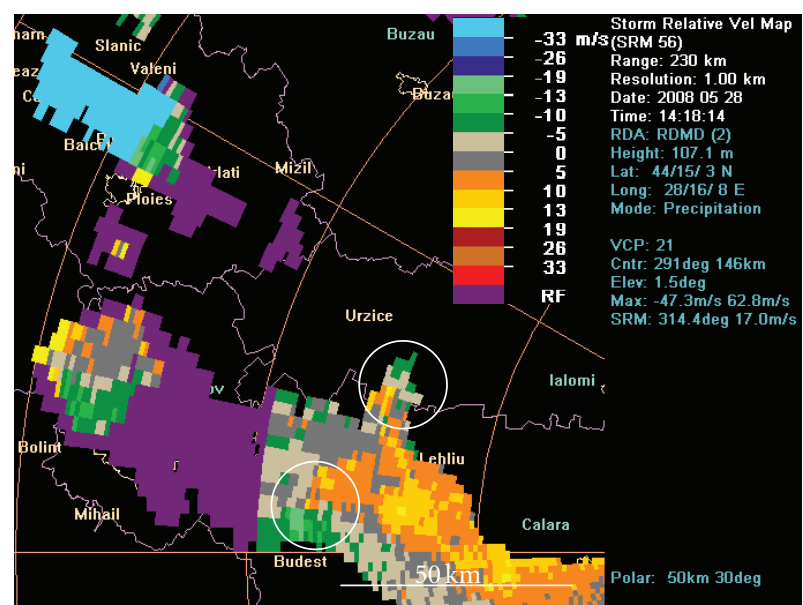

(b)

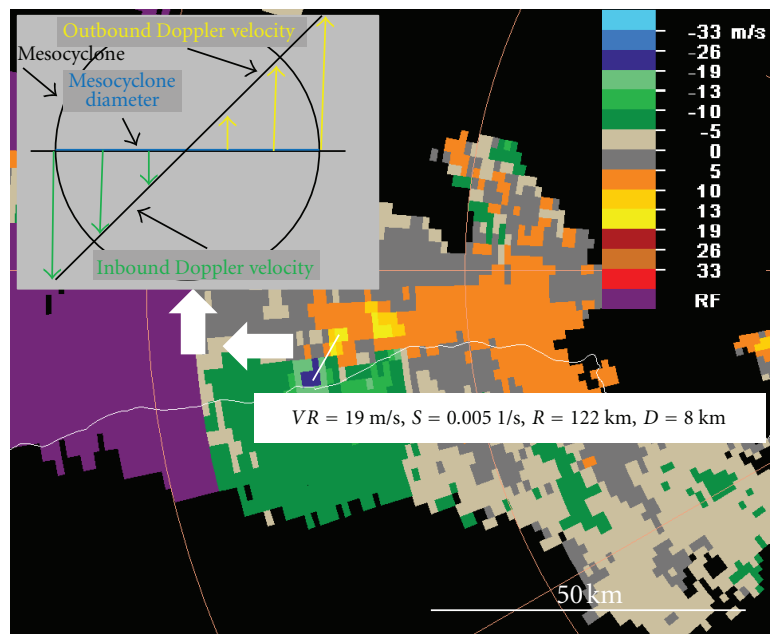

(c)

FIGURE 3: Radar reflectivity at 1.5-degree elevation (a), relative velocities at 1.5-degree elevation, (b) the white circles mark cyclonic and anticyclonic rotation associated with the two cells after the split, and shear due to the cyclonic and anticyclonic rotation (c). 


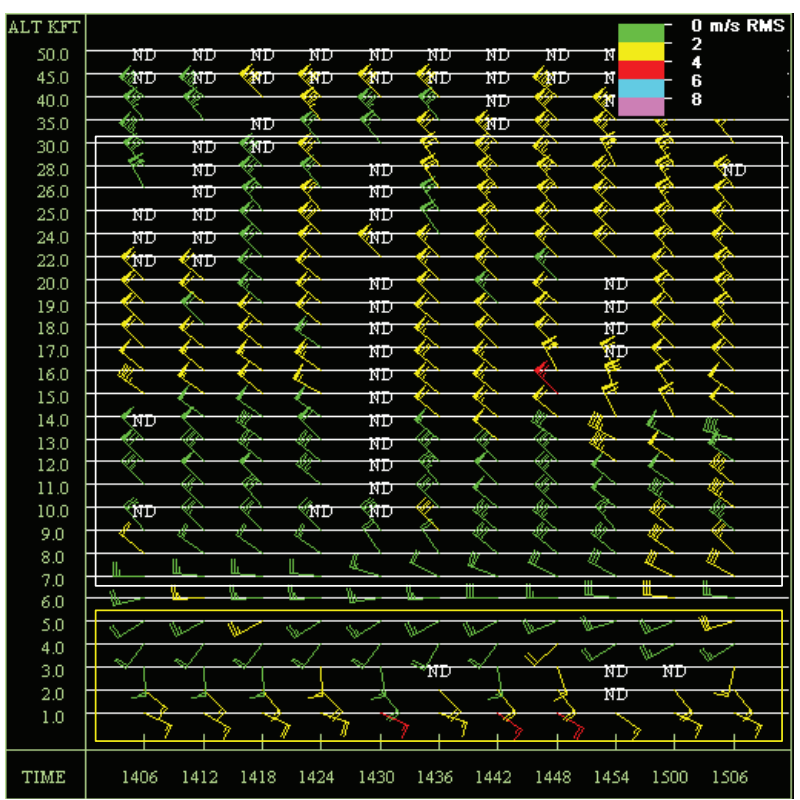

(a)

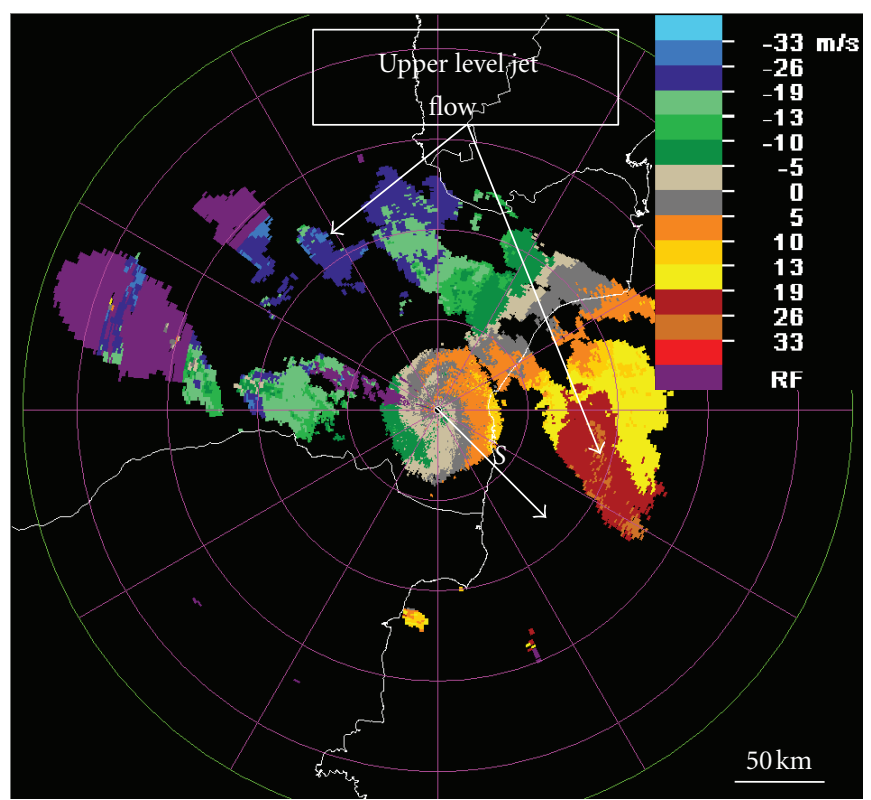

(b)

Figure 4: May 28, 2008, vertical profile of horizontal wind (VAD Wind Profile) for the 1406 UTC-1506 UTC (a) and (b) Doppler velocities at 3.4-degree elevation, at 1341 UTC. S vector represents the tropospheric mean shear at $1800-6000 \mathrm{~m}$. The flow is from north west and the jet is present at $5000-6000 \mathrm{~m}$.

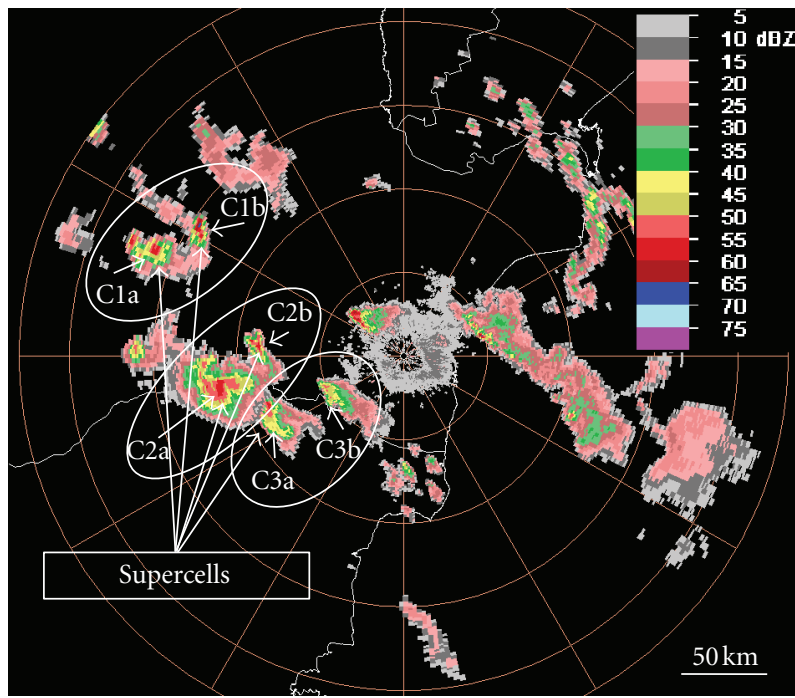

(a)

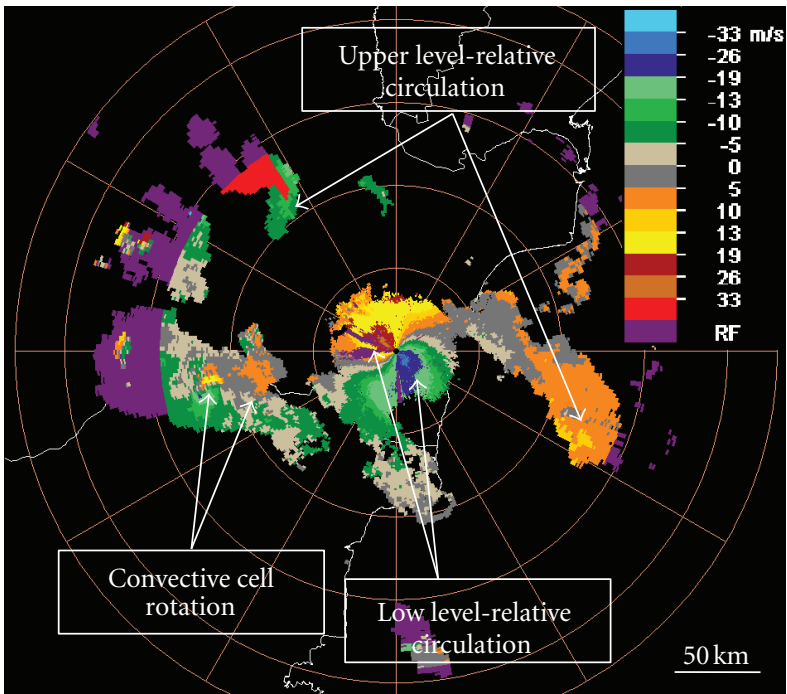

(b)

FIgURE 5: May 28, 2008, (a) radar reflectivity at 1.5-degree elevation, at 1500 UTC; (b) relative velocities at 2.4 degrees elevation, at 1500 UTC.

In the first three cases, this dynamic configuration is qualitatively compatible with Doppler velocity field at 3.4-degree elevation.

To analyse the presence of the cell splitting process of convective cells in south-eastern Romania and its role in supercell evolution, cases of severe weather were analysed where this process was shown clearly in the radar fields. For the first three cases, in the reflectivity field the convective cells were identified that split, and those that resulted from the split. Using the Doppler base velocity field at 3.4-degree elevation one can tell if there is a quality equivalence between the vertical profile of horizontal velocity near the radar station and the mesoscale flow. Trajectories of split cells were rebuilt, to identify some of their peculiarities. The trajectories were compared with the precipitation field, as obtained from WSR-98D S-band radar precipitation algorithm (Precipitation Processing System, PPS [37]).

The vertical profiles associated with horizontal vorticity were compared with vertical vorticities specific to cyclonic or anticyclonic rotation. In the last two cases, the presence of an upper-level jet was analysed, and the intensity of relative flow was examined. 


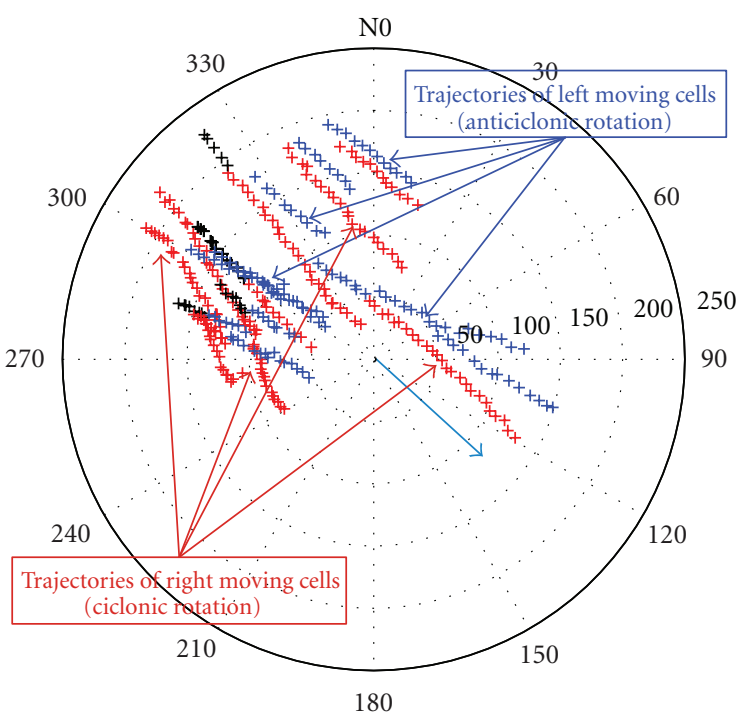

(a)

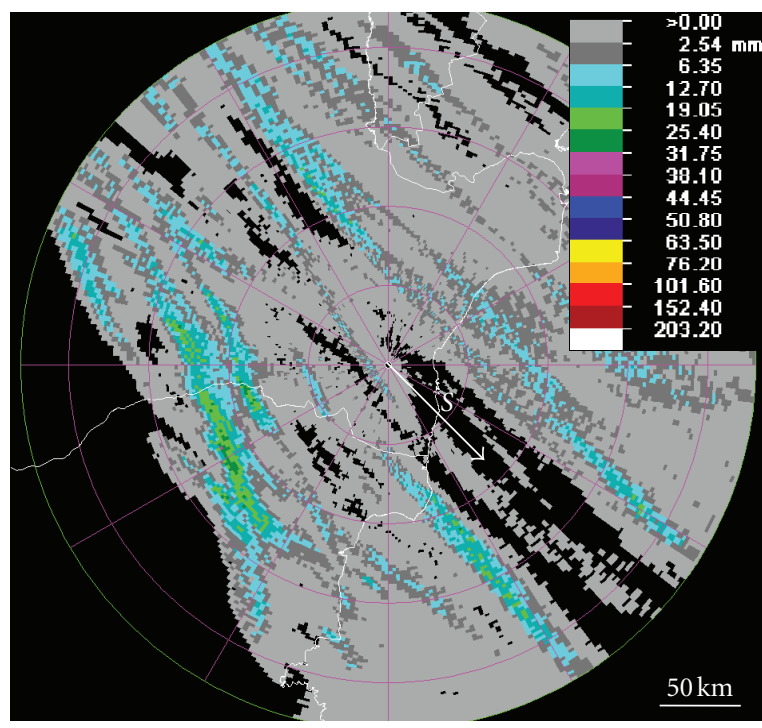

(b)

FIGURE 6: May 28, 2008, the convective cells evolution for 0900 UTC-2000 UTC using the Medgidia Doppler radar in (a). The center of images is the radar position. S vector represents the mean shear at $1800-6000 \mathrm{~m}$ altitude. Red stands for cyclonic rotation, blue for anticyclonic, and black signifies cells before split. The distance is measured in $\mathrm{km}$. The accumulated precipitations (mm), for 0900 UTC-2000 UTC (b).
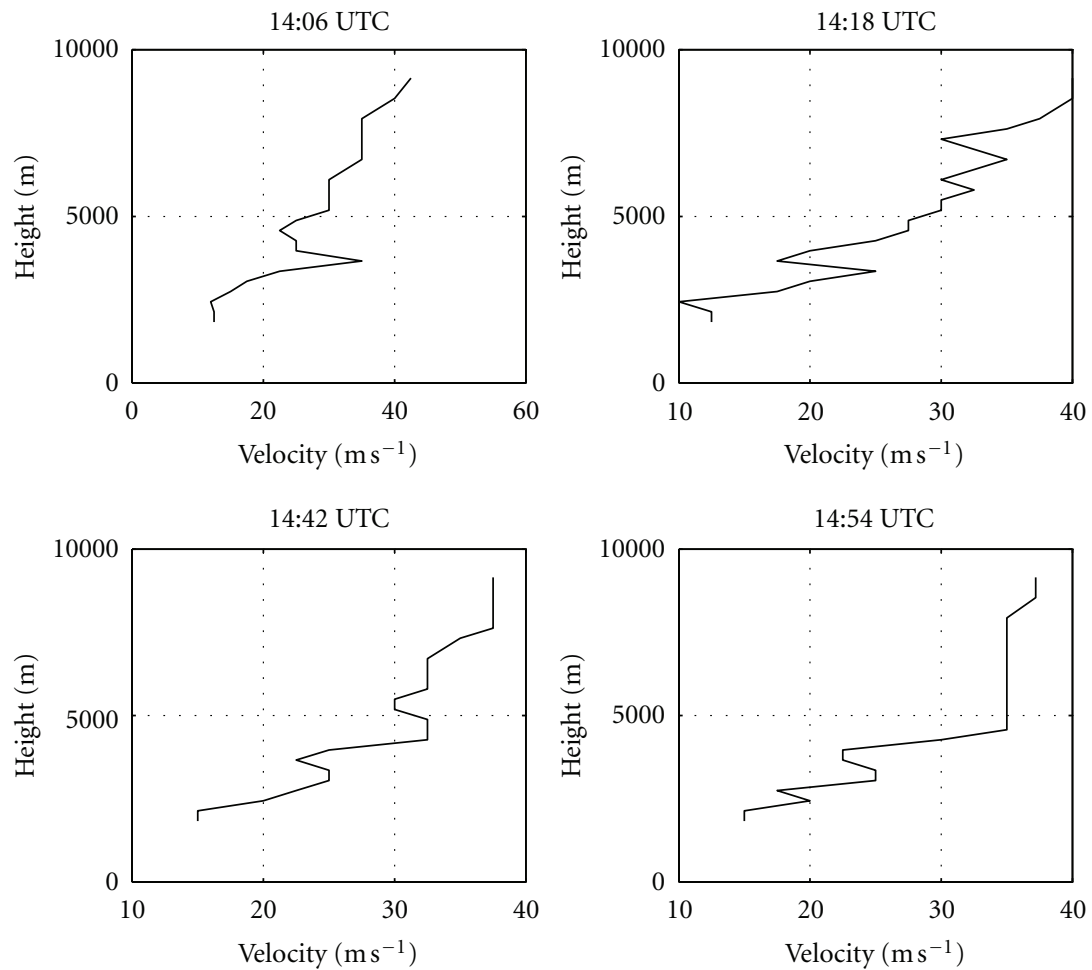
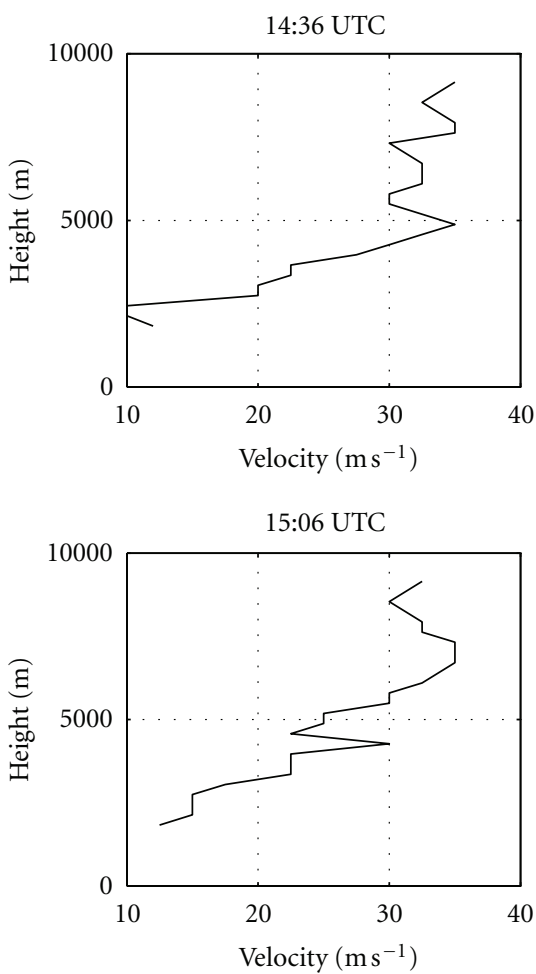

FIGURE 7: May 28, 2008, vertical velocity size distribution for 1800-9000 m altitude at 1406 UTC-1506 UTC.

\section{Results and Discussions}

3.1. The First Studied Case, May 28, 2008. A cyclone located in north-east Romania contributed to the instability conditions present in the Doppler radar area of the Medgidia site. Starting at 1130 UTC, on an NW-SE intense tropospheric circulation, convective cells developed in SE Romania that were split and became supercells. The most severe supercells were the ones with cyclonic rotation, such as those having the $\mathrm{V}$ shape in reflectivity field. Besides these, multicells systems were present in the radar field, with a lower degree of severity.

The temporal evolution of mesoscale flow is represented in Figure 4, between 1406 UTC and 1506 UTC, as seen in the VAD Wind Profile product and in the base Doppler velocities 

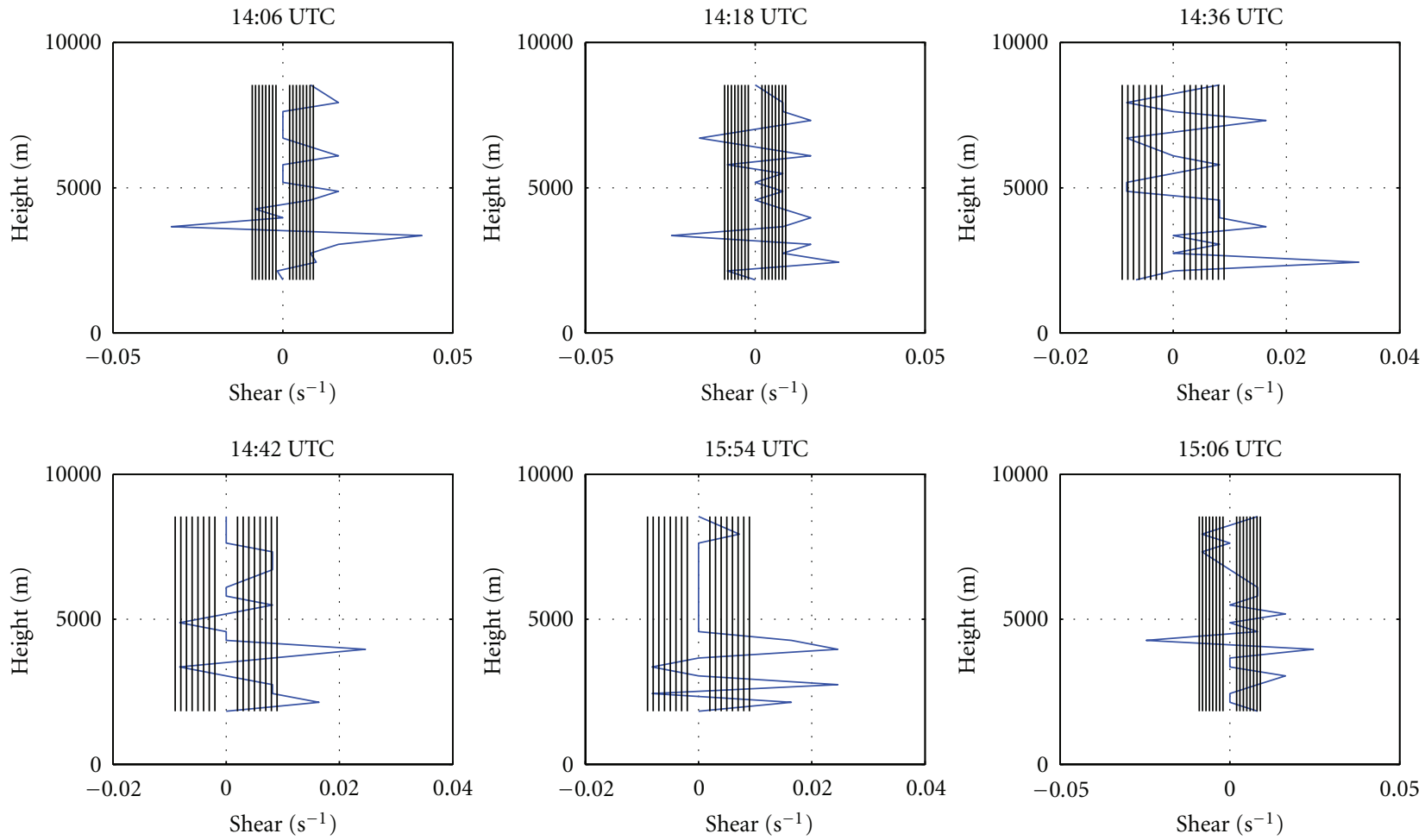

Figure 8: May 28, 2008, vertical shear distribution for 1800-9000 m layer, at 1406 UTC-1506 UTC (blue chart). Shear is calculated every $305 \mathrm{~m}$. Horizontal shear distribution associated with convective cells (vertical lines).

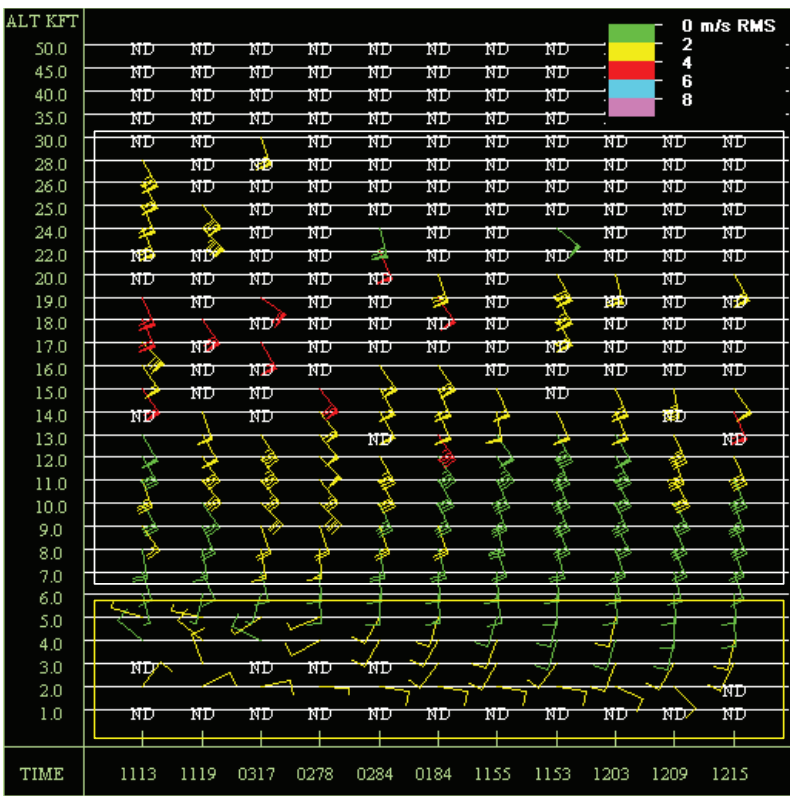

(a)

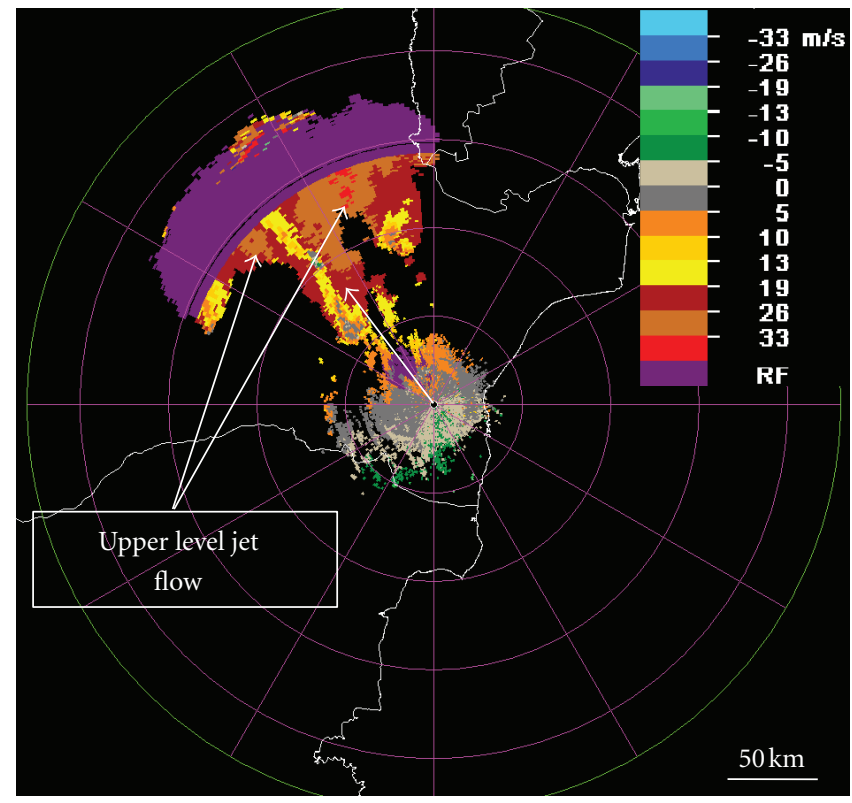

(b)

FIGURE 9: June 25, 2009, vertical profile of horizontal wind (VAD Wind Profile) for 1113 UTC-1215 UTC, using the Medgidia Doppler radar in S band in (a) and (b) Doppler velocities at 3.4 degrees elevation at 1341 UTC. The vector represents the mean shear for 1800-5000 m; the flow is from southeast and the jet is present at $4000-6000 \mathrm{~m}$. 


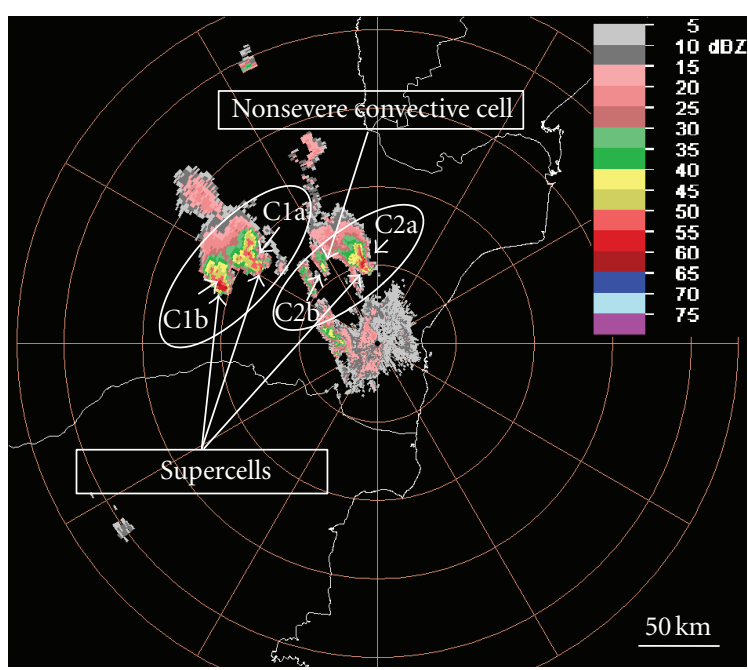

(a)

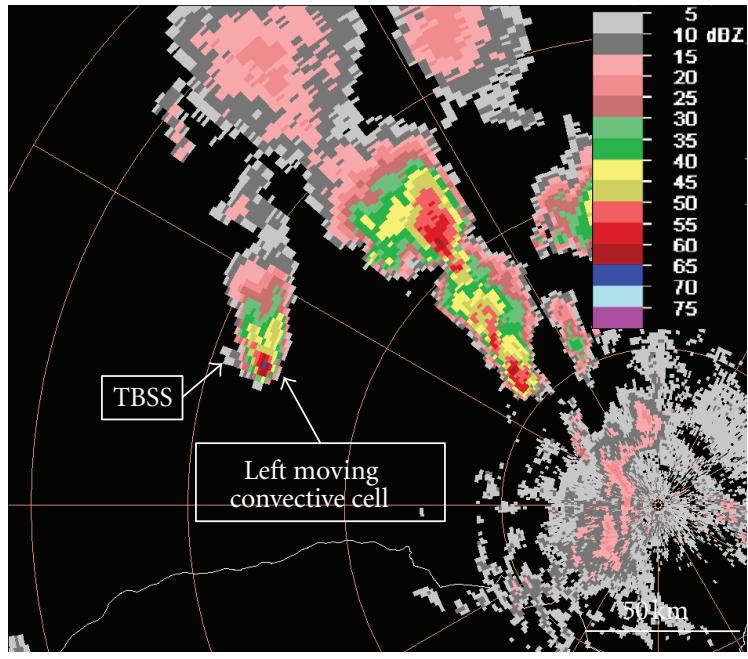

(c)

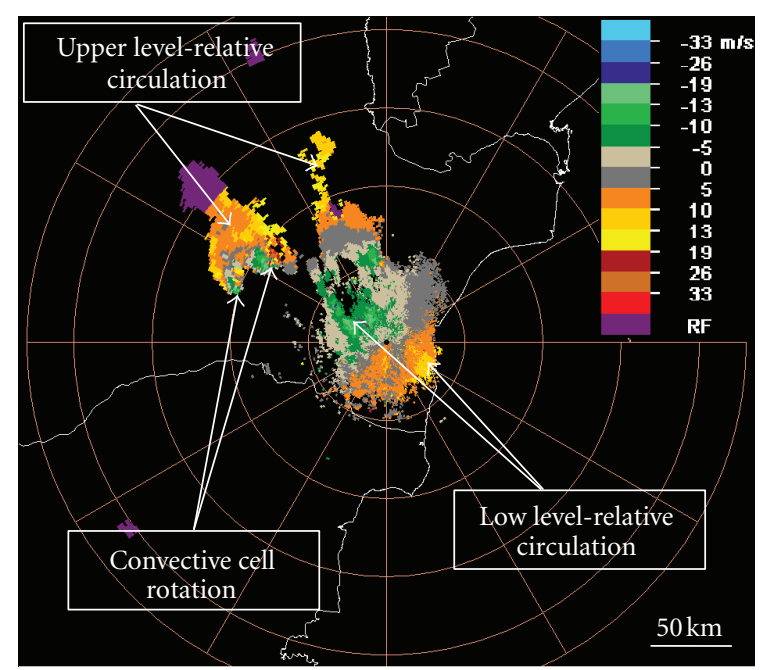

(b)

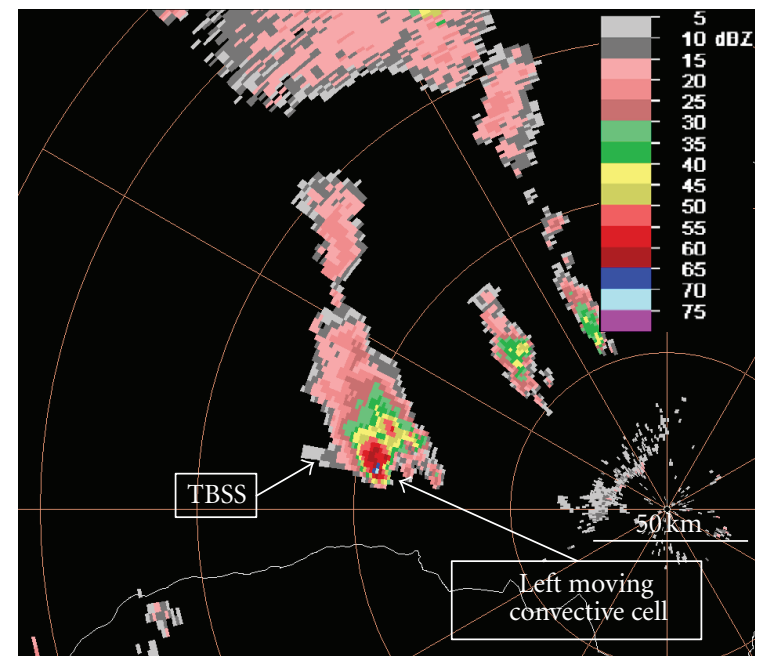

(d)

FIGURE 10: June 25, 2009, radar reflectvities at 2.4-degree elevation, at 1209 UTC (a). Doppler relative velocities at 2.4-degree elevation at 1209 UTC (b). Radar reflectvities at 1.5-degree elevation, at 1257 UTC, (c) and radar reflectvities at 2.4-degree elevation, at 1523 UTC (d).

field. The vertical wind profile was characterized by intense mesoscale flow from the north west to south east, above $1800 \mathrm{~m}$ (6 KFT) (Figure 4(a), in the white box). Below this level, from the VAD Wind Profile and base Doppler velocities, one can notice the anticyclonic rotation of velocity vector (Figure 4(a), in the yellow box).

At the $5000 \mathrm{~m}$ level, Figure 4(a), the values of velocity reach $35 \mathrm{~m} \mathrm{~s}^{-1}$ growing to $40-45 \mathrm{~m} \mathrm{~s}^{-1}$ at $35 \mathrm{KFT}(10500 \mathrm{~m})$. The colour for the wind vectors represents the level of confidence in the VAD Wind Velocity data; the level of confidence is larger in the lower troposphere (green, dispersion of $0-2 \mathrm{~m} \mathrm{~s}^{-1}$ ) and in the upper troposphere (yellow, dispersion of $2-4 \mathrm{~m} \mathrm{~s}^{-1}$ ). A larger dispersion of velocity is recorded in the lower layers (red, dispersion of $4-6 \mathrm{~m} \mathrm{~s}^{-1}$ ), which can be associated with different gust fronts caused by convective developments. In the same figure, both the anticyclonic rotation of the velocity vector in the lower two $\mathrm{km}$ and the upper tropospheric jet are consistent with the warm sector of the cyclone located north east of Romania. This vertical configuration of the horizontal velocity is also associated with increased thermodynamic instability in the troposphere below approximately $500 \mathrm{hPa}$; the main factor for the increase in conditional instability is moisture advection in the lower layers. However, the presence of a vertically expanded upper tropospheric jet is associated with ageostrophic velocities, which are the result of horizontal variation of the geostrophic velocities that lead to changes in the thermal gradient within the middle troposphere [18].

Vertical wind profile configurations of the mesoscale flow can be seen in the Doppler velocity field at 3.4-degree elevation (Figure 4(b)), and they are qualitatively equivalent with the vertical wind profile given by the VAD Wind Profile product. This equivalence is the result of the zero isodope analysis [34] in the Doppler velocity field. The zero isodope represents the area where the Doppler velocities are zero (gray 

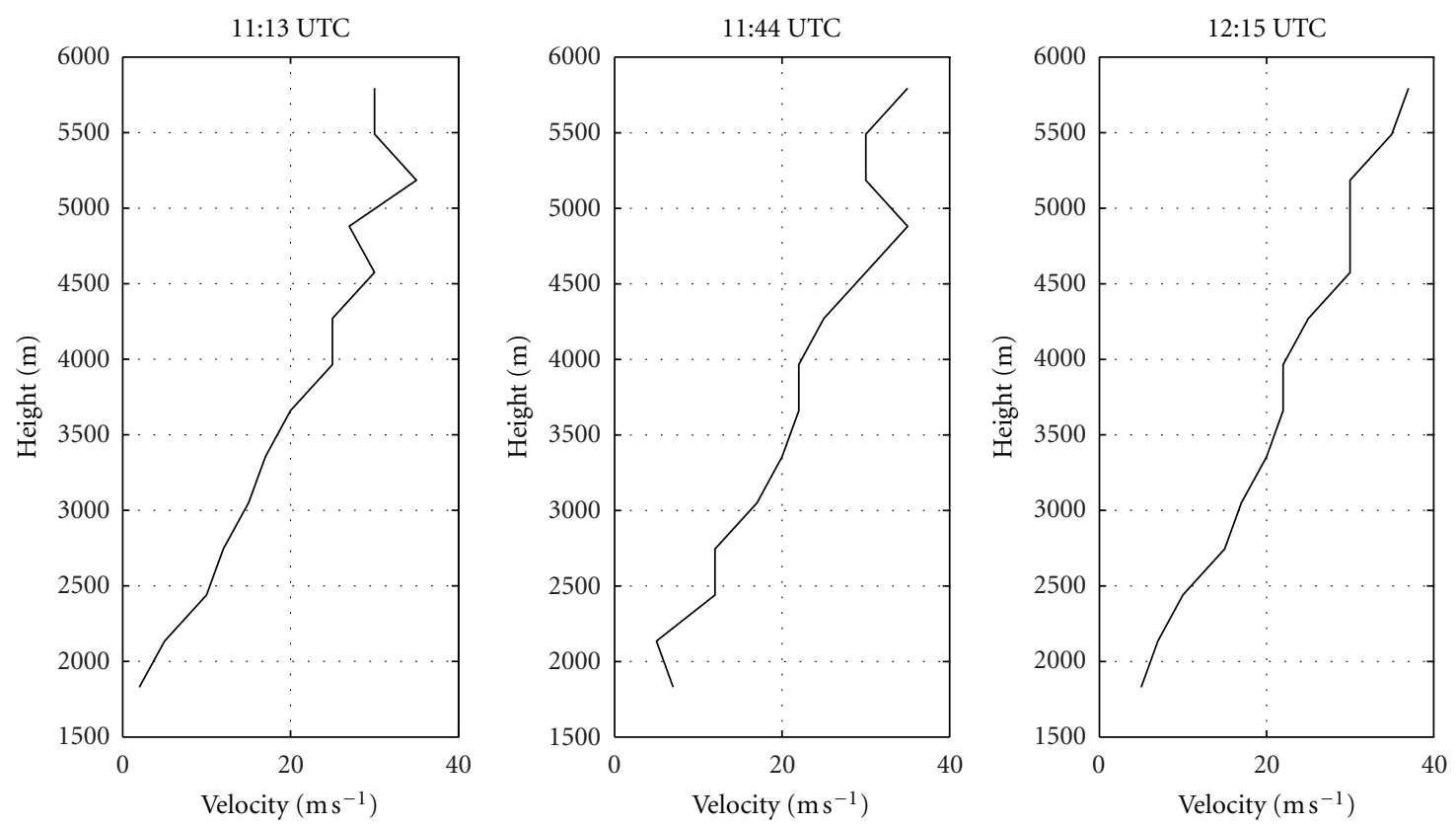

FIgURE 11: June 25, 2009, vertical velocity size distribution for 1800-6000 m, at 1113 UTC-1215 UTC.
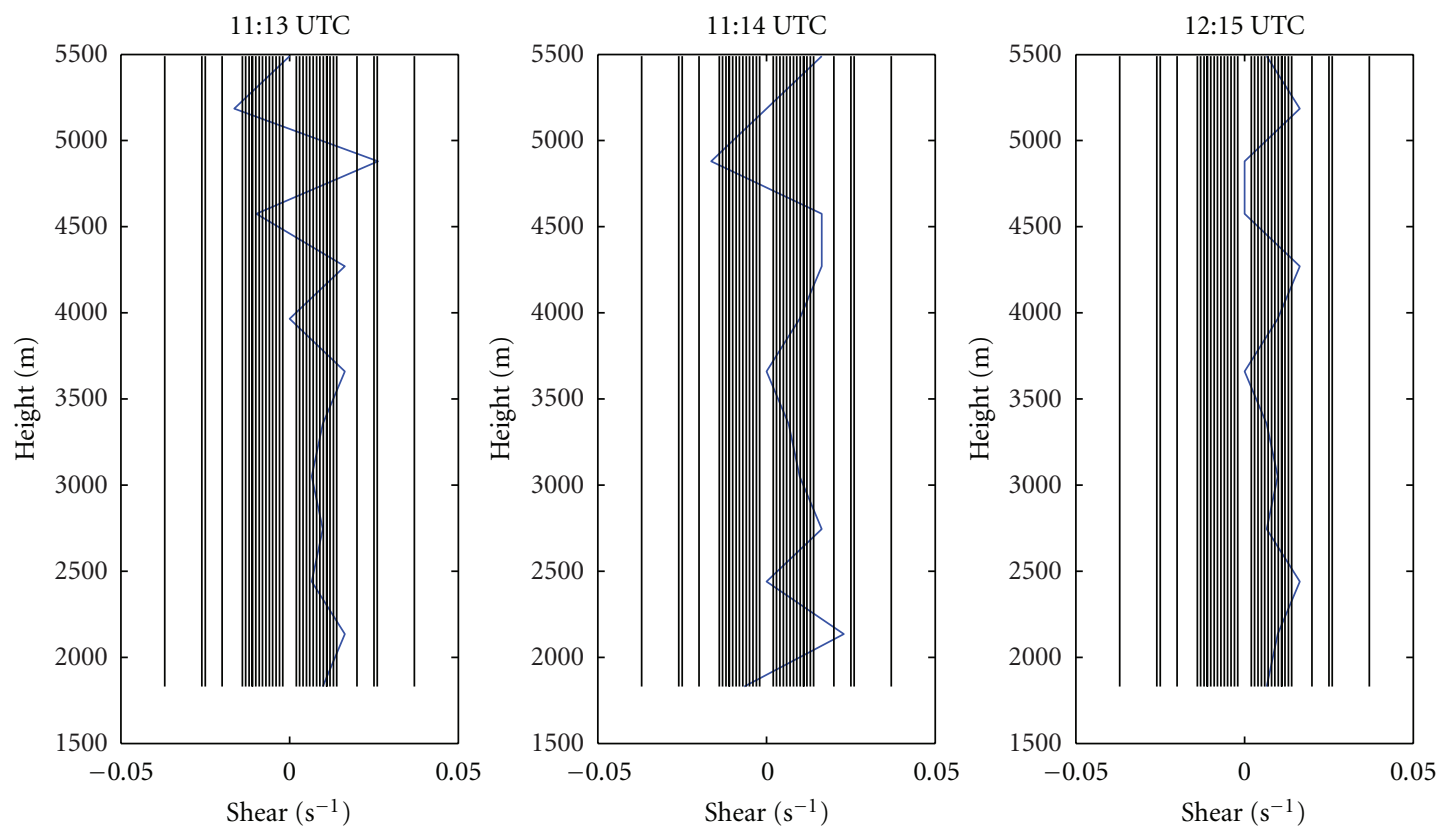

FIGURE 12: June 25, 2009, vertical shear distribution for 1800-6000 m, at 1113 UTC-1215 UTC (blue chart). Shear is calculated every $305 \mathrm{~m}$. Horizontal shear distribution associated with convective cells (vertical lines).

colours, in Figure 4(b)). Near the radar site (in the boundary layer) the isodope is $\mathrm{S}$ shaped, compatible with the velocities profile (within the yellow box, in Figure 4(a)). Going away from the radar (increasing the height), this has a linear shape on the NE-SW direction and is compatible with the upper tropospheric jet direction (Figure 4(a)). The intensity of the jet stream is obtained by measuring the Doppler velocities at 90 degrees from the isodope, having the same height (same distance from the radar in the Doppler velocity field).
The dynamic field of the Doppler velocities was maintained over the interval with the mentioned convective phenomena (a few hours). In Figure 5(a) the reflectivity field is shown at 1500 UTC at 1.5-degree elevation, and in Figure 5 (b) the Doppler relative velocity field is shown at 2.4-degree elevation at 1500 UTC. The reflectivity field at each elevation has a $1 \mathrm{~km}^{2}$ resolution with a coverage area of $230 \mathrm{~km}$ radius around the radar site and the corresponding product is built every 6 minutes. The angle of the radar azimuth beam is about 


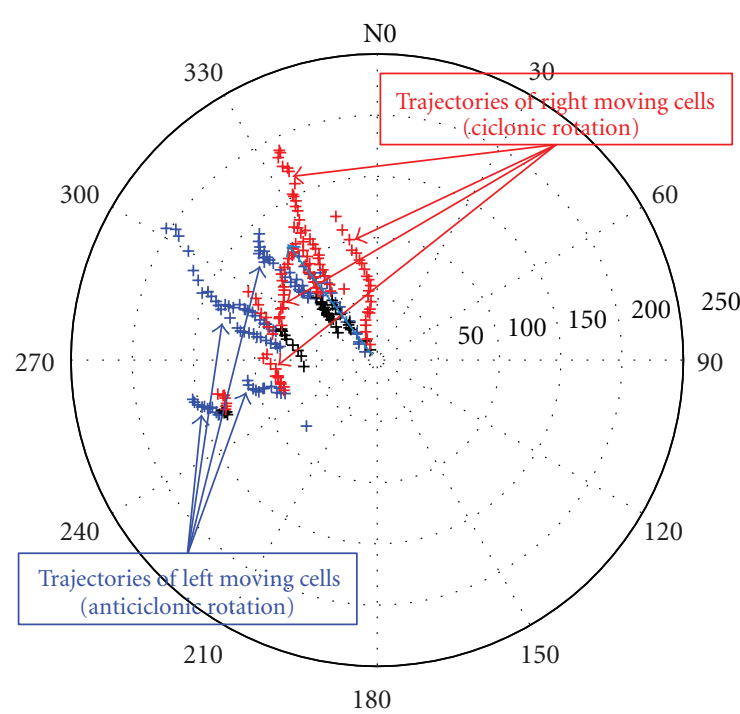

(a)

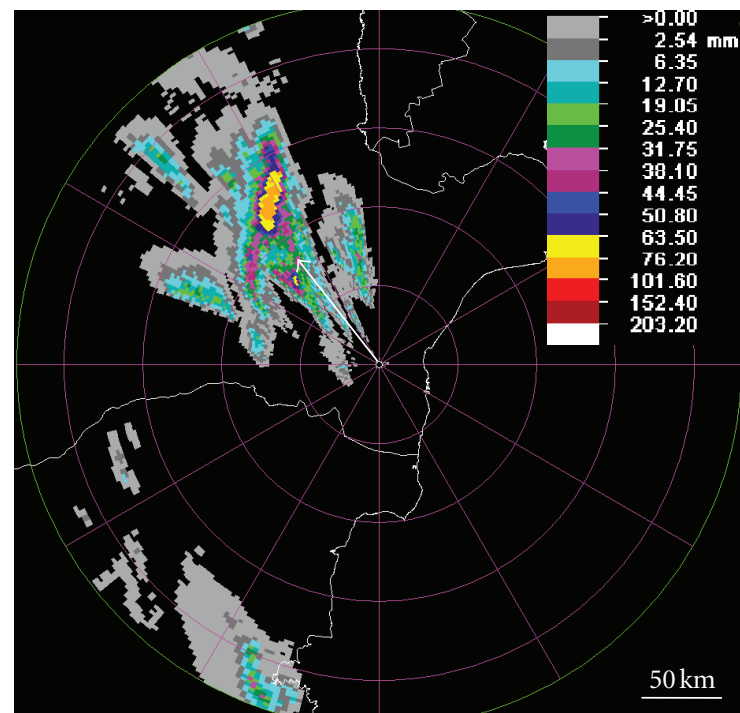

(c)

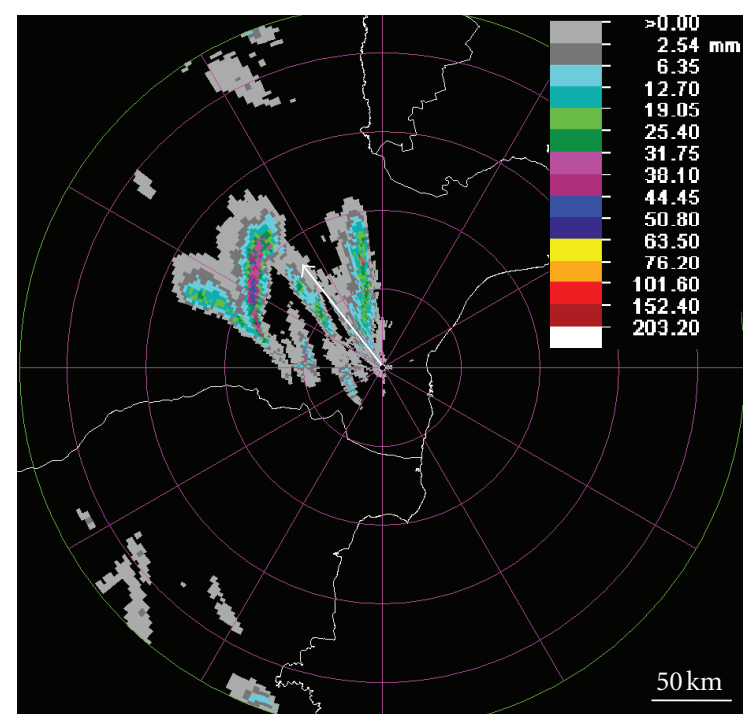

(b)

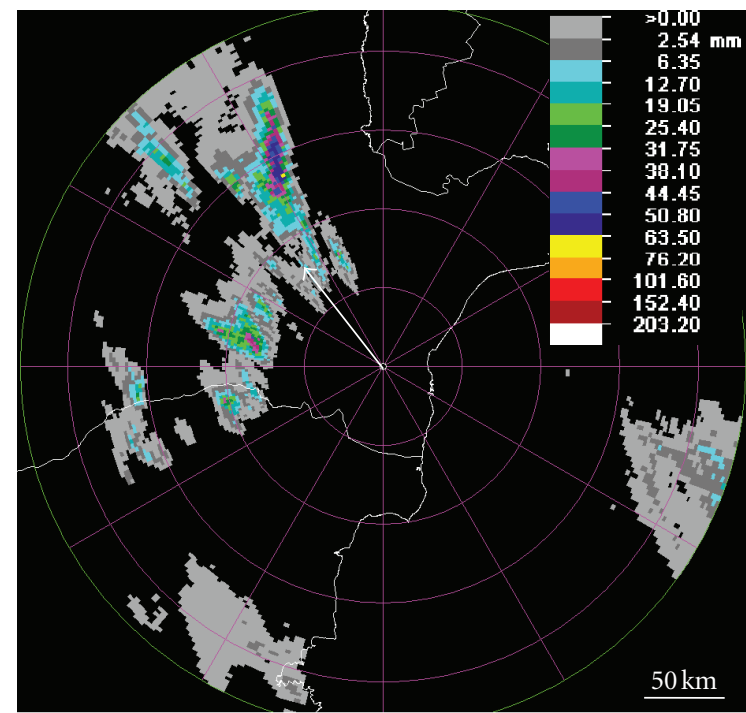

(d)

FIGURE 13: June 25, 2009, the convective cells evolution at 1030 UTC-1800 UTC using the Medgidia Doppler radar in (a). The white vector represents the mean shear for 1800-5000 m altitude. Red is the cyclonic rotations and blue is the anticyclonic rotations. The distance is in $\mathrm{km}$. Accumulated precipitations are for every three hours: (b) 1040 UTC-1340 UTC, (c) 1205 UTC-1505 UTC, and (d) 1405 UTC-1705 UTC.

0.97 degrees, so that 366 azimuths are needed to cover the entire radar area. At 1.5-degree elevation (Figure 5(a)), as the height of the radar echo increases along with the distance to the site at $230 \mathrm{~km}$ from the site the height is $9.6 \mathrm{~km}$. In Figure 5(a), the Doppler velocities field relative to the storm is at 2.4degree elevation, and at the $230 \mathrm{~km}$ the height is $13.2 \mathrm{~km}$.

In the reflectivity field, six convective cells can be seen, resulting from three convective cells that had split, and in the relative Doppler velocity field the rotation can be seen, associated with resulted convective cells. A fundamental feature is the relative jet at 100-1000 $\mathrm{m}$ with velocities of up to $29 \mathrm{~m} \mathrm{~s}^{-1}$. This relative jet is the storm input flow and can only be observed in the storm's reference frame; it may be associated with the moisture inflow. Above $6000 \mathrm{~m}$ there is a relative flow with velocities up to $11 \mathrm{~m} \mathrm{~s}^{-1}$.

Trajectories of convective cells that had split during evolution present symmetry to the mean shear in the 1800-6000 m layer (blue arrow), with cells characterised by cyclonic rotation left of the vector and anticyclone rotation right of it (Figure 6(a)). In Figure 6(a), advection of convective cells by the tropospheric circulation is on the NW$\mathrm{SE}$ direction. In this case, because the flow is parallel wih the shear vector on the mean troposhere, the convective cells with cyclonic rotation (red) deviate to the right and the ones with anticyclonic rotation (blue) to the left of this direction. Following the cell evolution, the intensity of the cyclonic 


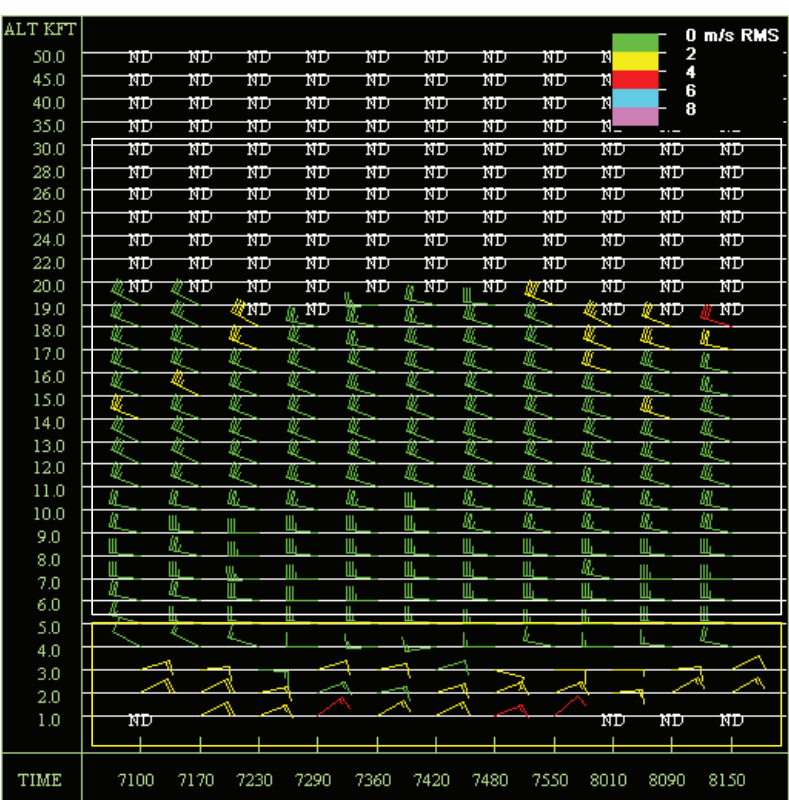

(a)

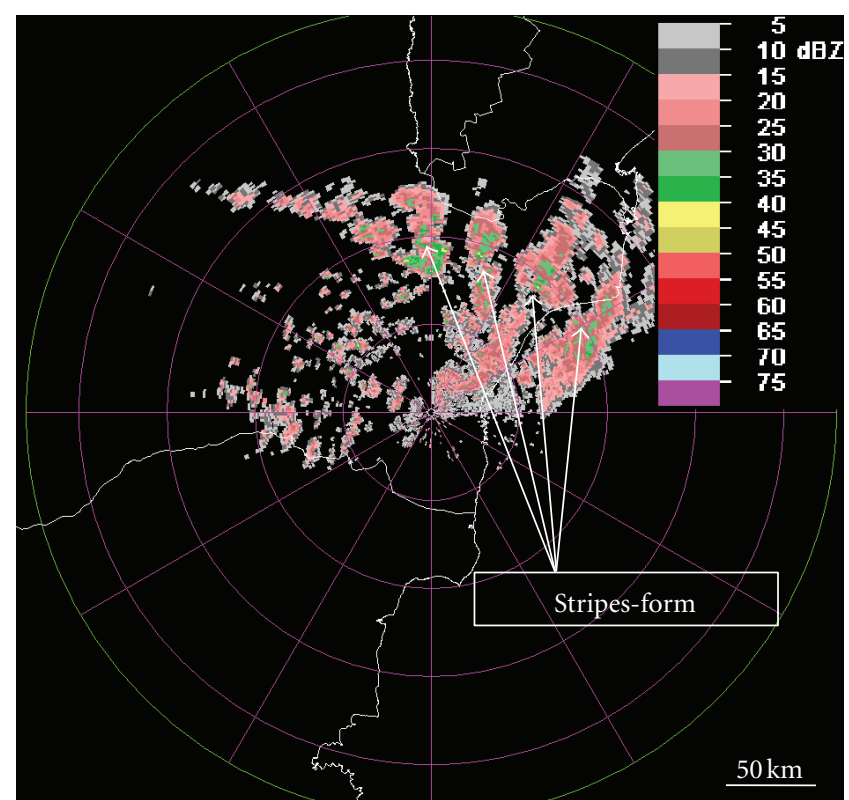

(b)

Figure 14: August 11, 2003, (a) vertical profile of horizontal wind (VAD Wind Profile) for 300-5800 m, at 0710 UTC-0815 UTC; (b) reflectivity field at 1.5-degree elevation.

rotation is larger than that of anticyclonic rotation. The cause for this difference can be associated with directional shear in the 300-1800 $\mathrm{m}$ layer and is favoured by advection of vorticity, whose vector is parallel to the wind relative to the storm $[17,18]$.

The splitting process may occur several times in the cells following from a previous split. For multiple splits, cells are favoured whose movement occurs on the left of the mean tropospheric shear. One possible explanation is that these cells draw more vorticity from their surroundings, vorticity which is perpendicular to the relative storm flow [18].

Cumulative rainfall in the evolution area, associated to the convective cells, is presented in Figure 6(b). The maximums are associated with convective cells, appearing as lines with symmetrical shear. Trajectories associated with more precipitation are to the right of shear in the $1800-6000 \mathrm{~m}$ layer. The amount of precipitation is amplified by the intersection of convective cells paths (cells with cyclonic rotation intersect those with anticyclonic rotation); indeed, in Figure $6(\mathrm{a})$, these intersections are more likely to the right of the mean shear vector.

Vertical wind variation associated with VAD Wind Profile, Figure 4(a), is represented for 6 times in Figure 7. Note the presence of the tropospheric jet in the 1800-9000 m layer, with values of about $40 \mathrm{~m} \mathrm{~s}^{-1}$ at $9000 \mathrm{~m}$. The vertical profile of horizontal vorticity versus vertical vorticity associated with cell rotation is given in Figure 8; here, vorticity was calculated every $305 \mathrm{~m}$ on the $z$-axis. One can see several maximum values of vorticity. The highest values are found in the 2000-4000 m layer. The horizontal vorticity of the environment (Figure 8, blue chart) was superimposed over cyclonic or anticyclonic vertical vorticity associated with mesocyclones (Figure 8, vertical lines) in the radar area. The parallel lines with vertical axes signify the vorticity of mesocyclones calculated with the radar algorithm in Figure 3(c). Vorticity was plotted both with a plus and minus sign for symmetry, to be more easily compared with the horizontal vorticity of the environment.

3.2. The Second Studied Case, June 25, 2009. The presence of a stationary cyclone in the SE of Romania modulated the mesosynoptic configuration in which severe convective cells developed. These cells had supercellular attributes and had an SE-NE direction in the S-band WSR-98D radar area (located in Medgidia). In the first stage, convection had an isolated character and formed near the radar site. Afterwards, the majority of cells split and became supercells. In the end, the cells with cyclonic rotation formed a convective system. Similarly to the previous case, the vertical velocity profile is characterized by an intense mesoscale flow above $1800 \mathrm{~m}$ (6 KFT) (Figure 9(a), the white box). Below this level, between 1113 UTC and 1215 UTC, in the same figure one can see the rotation of velocity vector along the $z$-axis (this rotation may be associated with directional shear) (the yellow box, in Figure 9(a)).

Above $1800 \mathrm{~m}$, there is strong intensification of wind, associated with the presence of a ULJ from south east; this ULJ reaches $35 \mathrm{~m} \mathrm{~s}^{-1}$ at $5000 \mathrm{~m}$. The dynamic field that can be viewed in the Doppler velocities, Figure 9(b), retained its structure between 1030 UTC and 1800 UTC.

Radar reflectivities show four secondary convective cells that are resulted from the splitting of two initial cells 

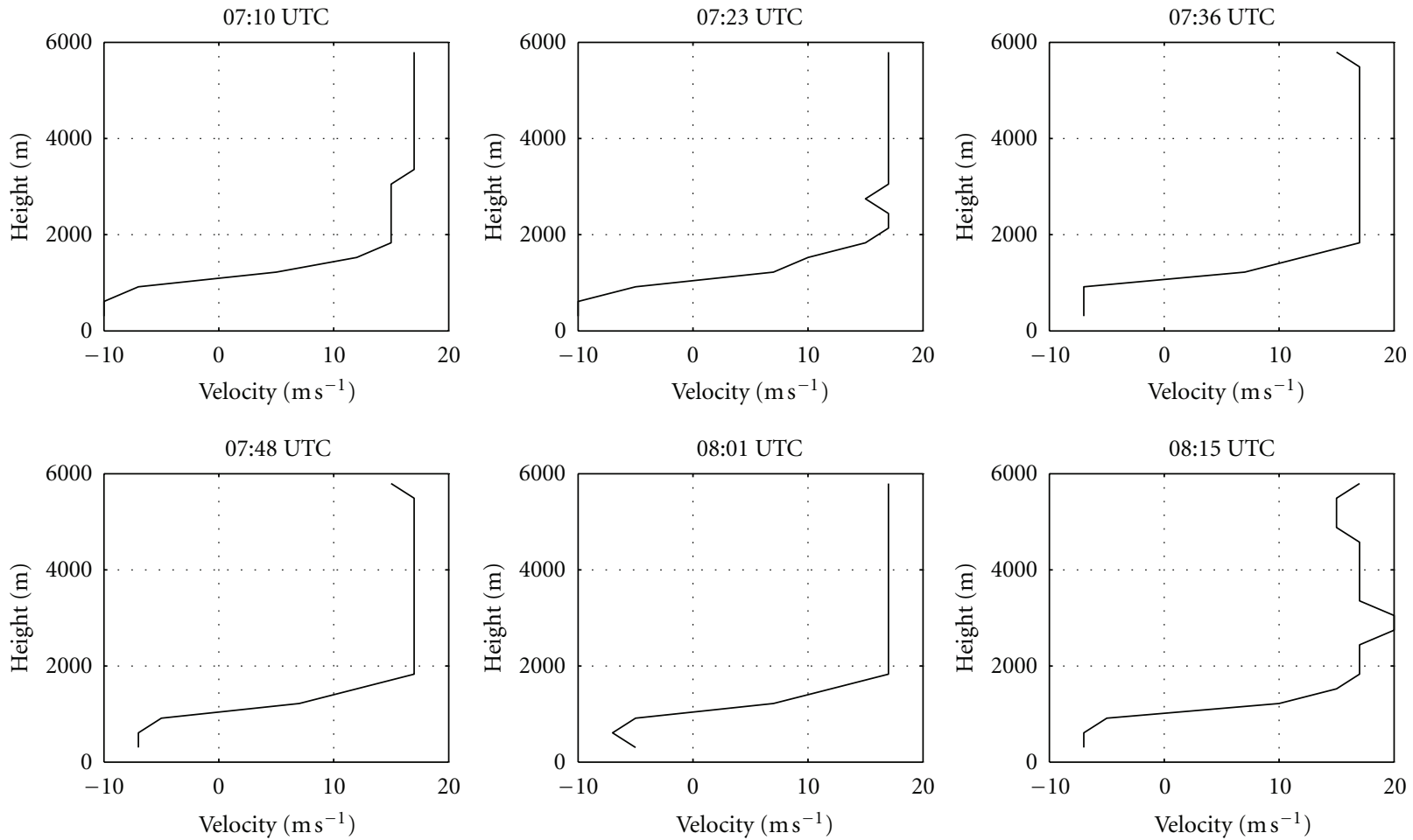

FIGURE 15: August 11, 2003, vertical velocity size distribution for 300-5800 m, at 0710 UTC-0815 UTC.
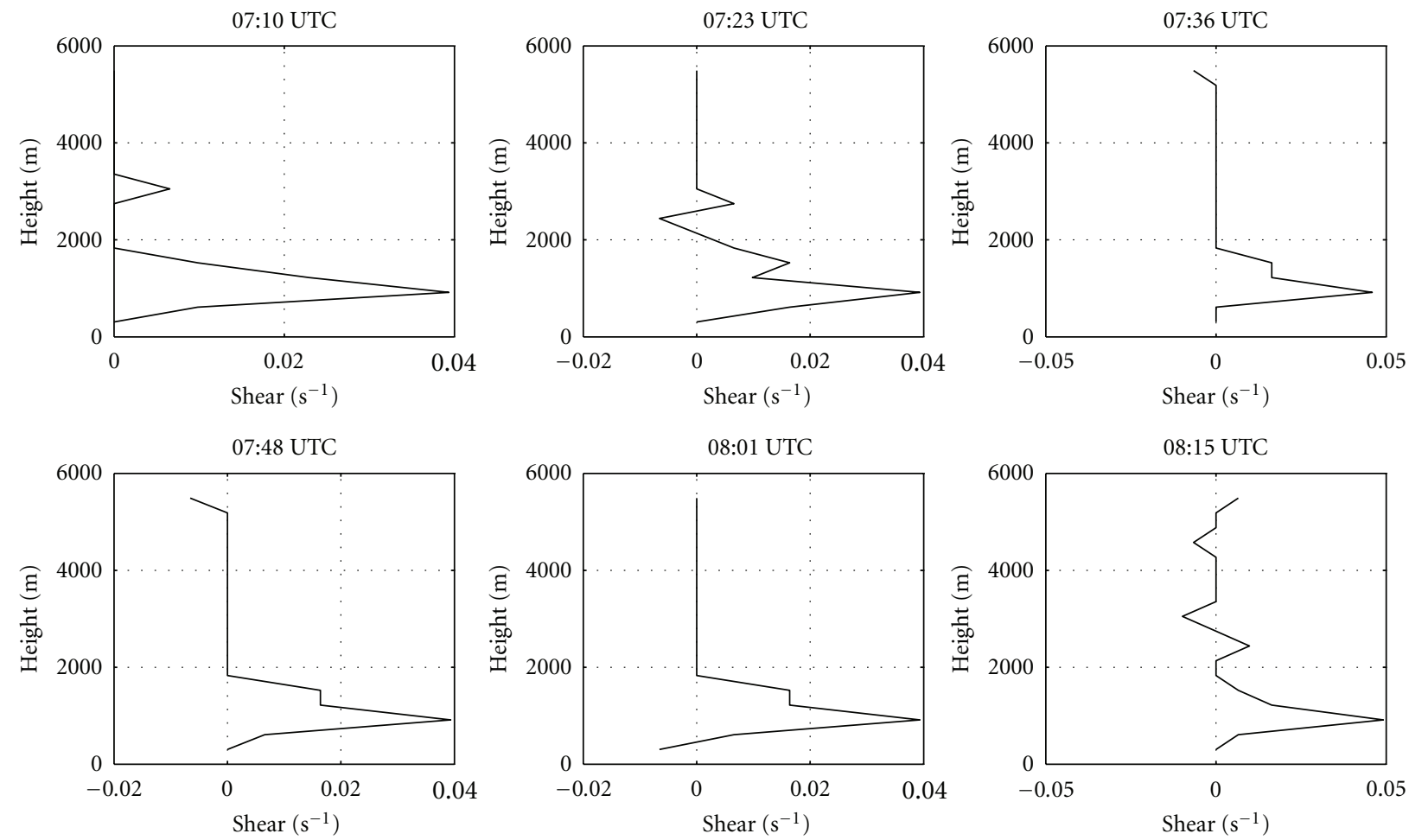

FIgURE 16: August 11, 2003, vertical shear distribution for 300-5800 m, at 0710 UTC-0815 UTC. Shear is calculated every 305 m. 


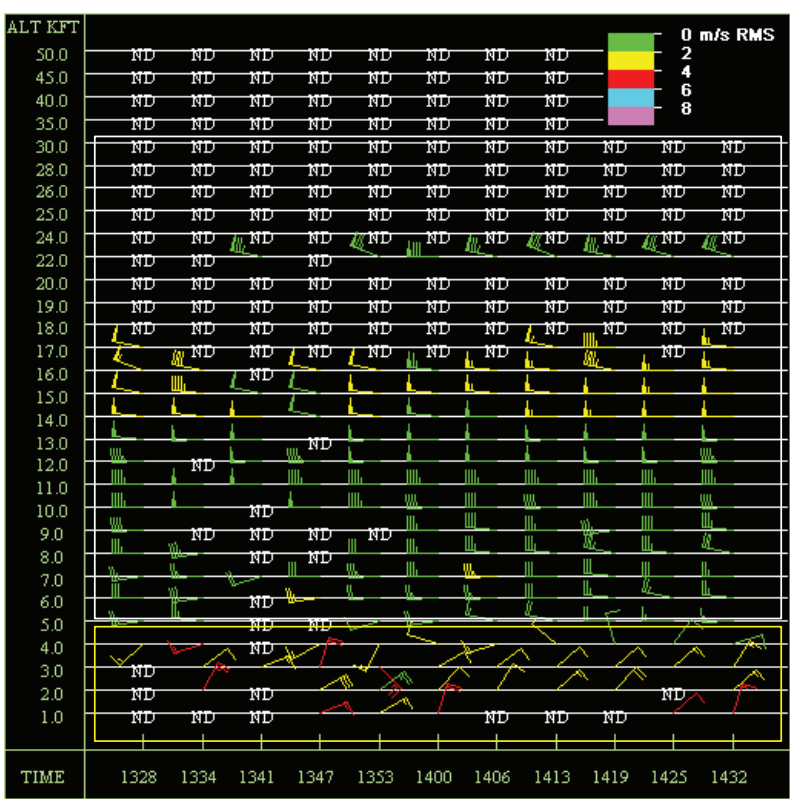

(a)

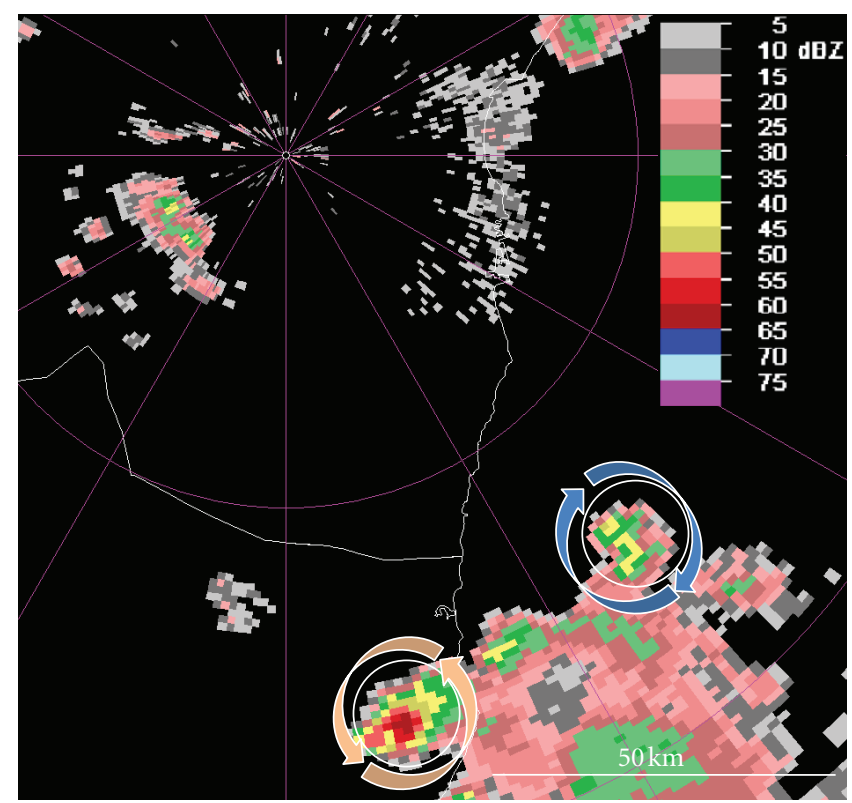

(b)

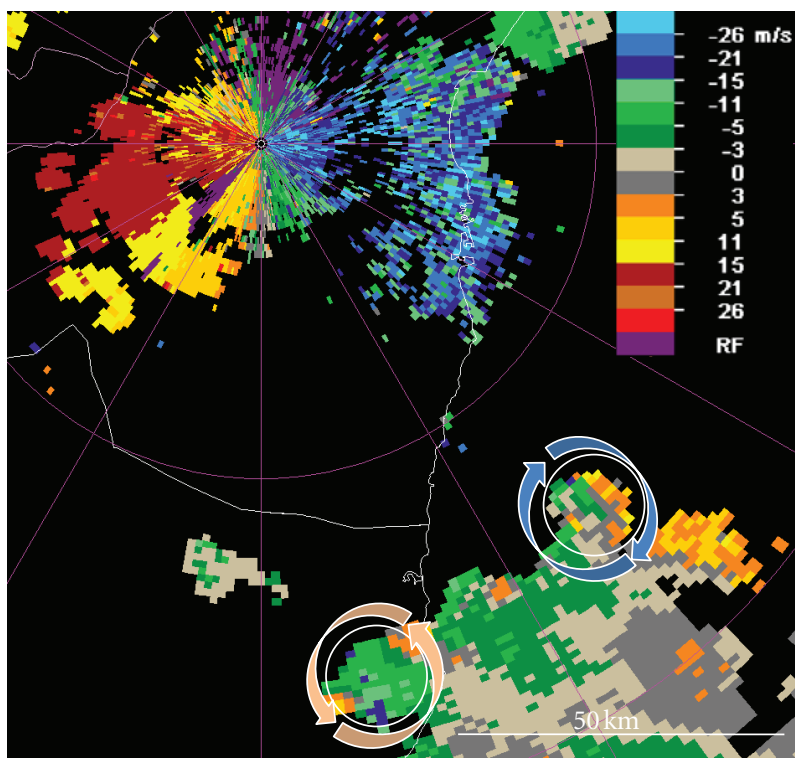

(c)

FIgURE 17: August 11, 2003, (a) vertical profile of horizontal wind (VAD Wind Profile) for 1500-6700 m, at 1328 UTC-1432 UTC; (b) radar reflectivity at 1.5-degree elevation, at 1400 UTC and (c) Doppler relative velocities at 1.5-degree elevation, at 1400 UTC.

(Figure 10(a)). Three of them are supercells, and one is nonsevere. In the field of relative Doppler velocities a relative jet is present whose speed is up to $16 \mathrm{~m} \mathrm{~s}^{-1}$ at $1000 \mathrm{~m}$, while above $5000 \mathrm{~m}$ intense circulation is present, with up to $16 \mathrm{~m} \mathrm{~s}^{-1}$, (Figure 10(b)). The refletivity field and the relative velocity characteristics are the same as in the pevious case.

Severe storms moving towards the left of mean shear (anticyclonic rotation) were characterized by high intensity and shorter lifespan and were associated with the presence of Three-Body Scatter Spike (TBSS) radar artifact (Figures 10(c) and $10(\mathrm{~d})$ ). This artifact is a radar signature in reflectivity field, generally a $10-30 \mathrm{~km}$ long, aligned radially downrange from a strong echo region in reflectivity field (>60 dBZ) associated with a severe storm. It is caused by non-Rayleigh radar microwave scattering or Mie scattering and is asociated with high probability of large hail [38-40].

In Figure 11 three vertical velocity profiles are presented, at certain times representative for this case. Here, the tropospheric ULJ has $35-40 \mathrm{~m} \mathrm{~s}^{-1}$ at $6000 \mathrm{~m}$. The vorticity profile is shown in Figure 12 (blue chart).

The mesocyclone vorticities associated with convective cells that splited are represented by parallel lines with the vertical axes (Figure 12). Note that most values of vorticity lie between $-0.005 \mathrm{~s}^{-1}$ to $-0.015 \mathrm{~s}^{-1}$ and $0.005 \mathrm{~s}^{-1}$ to $0.015 \mathrm{~s}^{-1}$. 

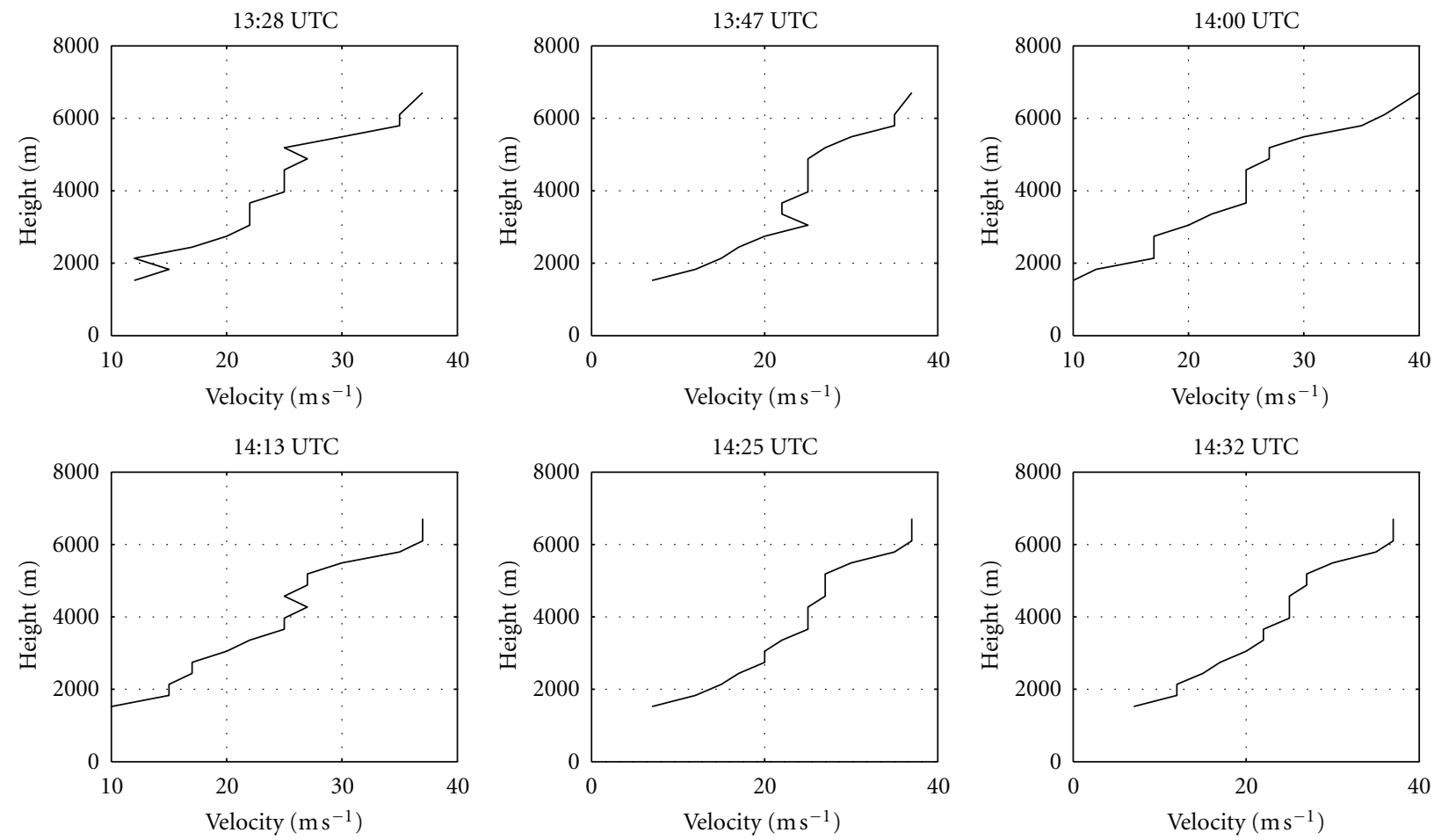

FIGURE 18: August 11, 2003, vertical velocity size distribution for 1500-6700 m, at 1328 UTC-1432 UTC.
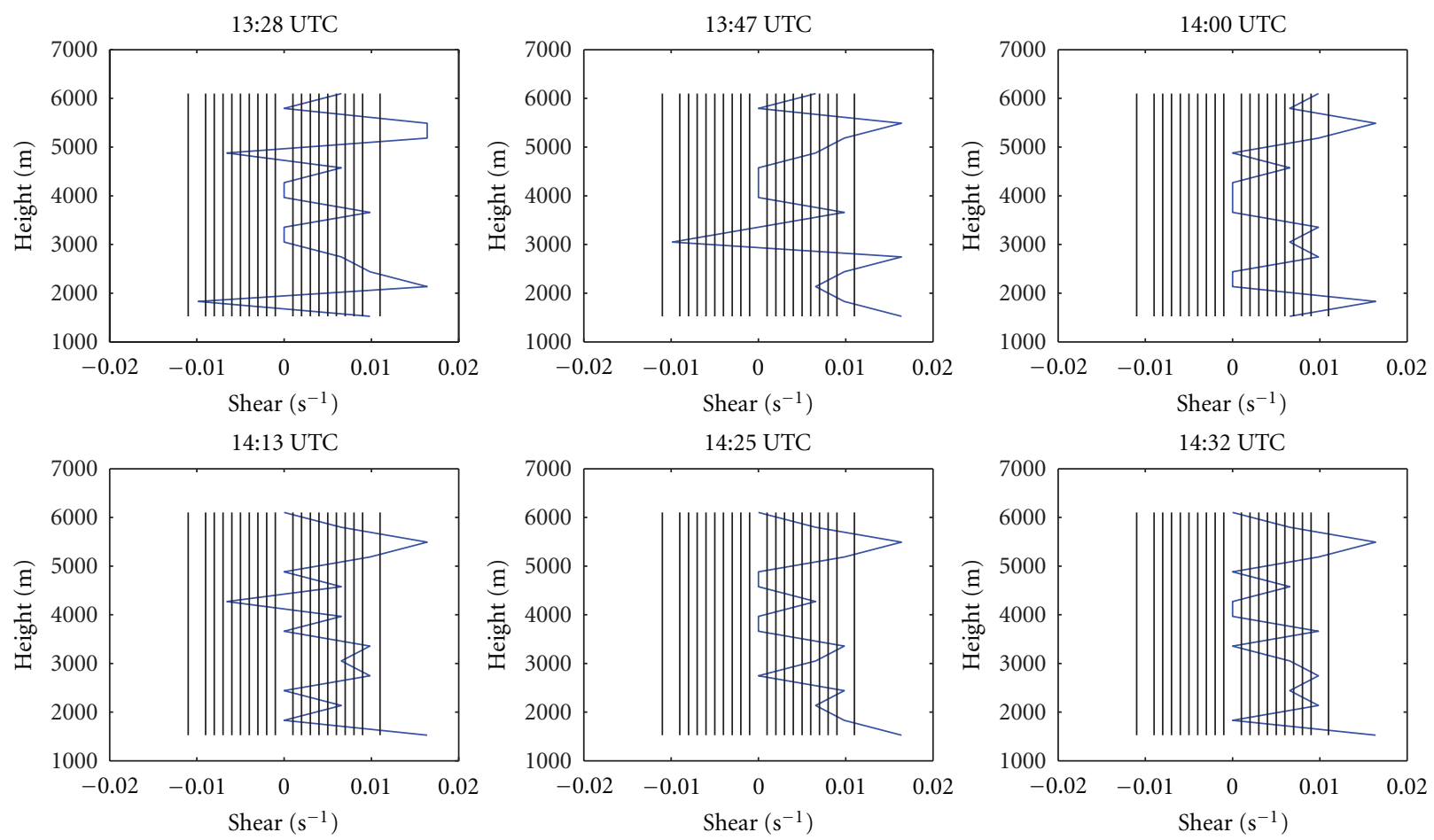

FIgURE 19: August 11, 2003, vertical shear distribution for 1500-6700 m, at 1328 UTC-1432 UTC (blue chart). Shear is calculated every $305 \mathrm{~m}$. Horizontal shear distribution associated with convective cells (vertical lines). 


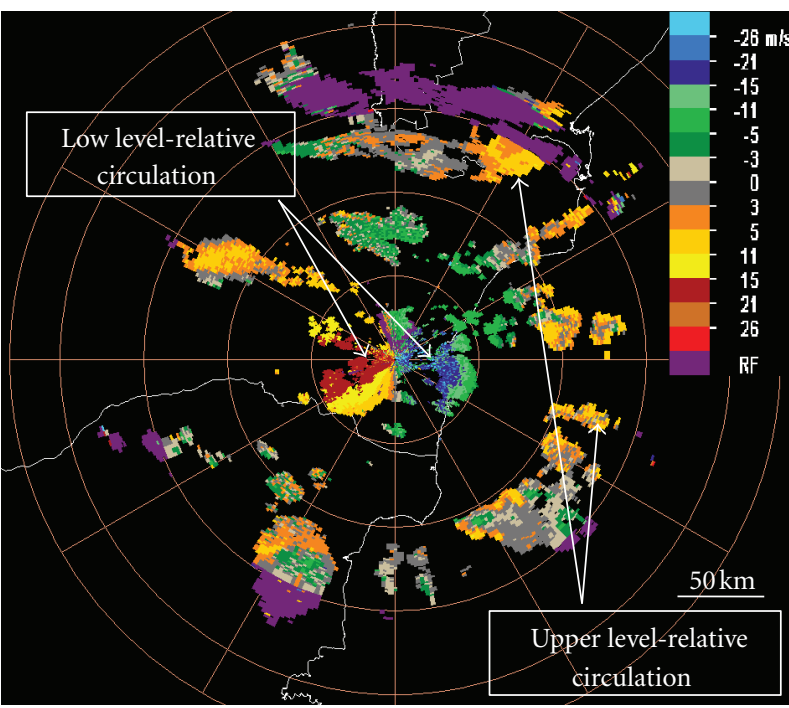

(a)

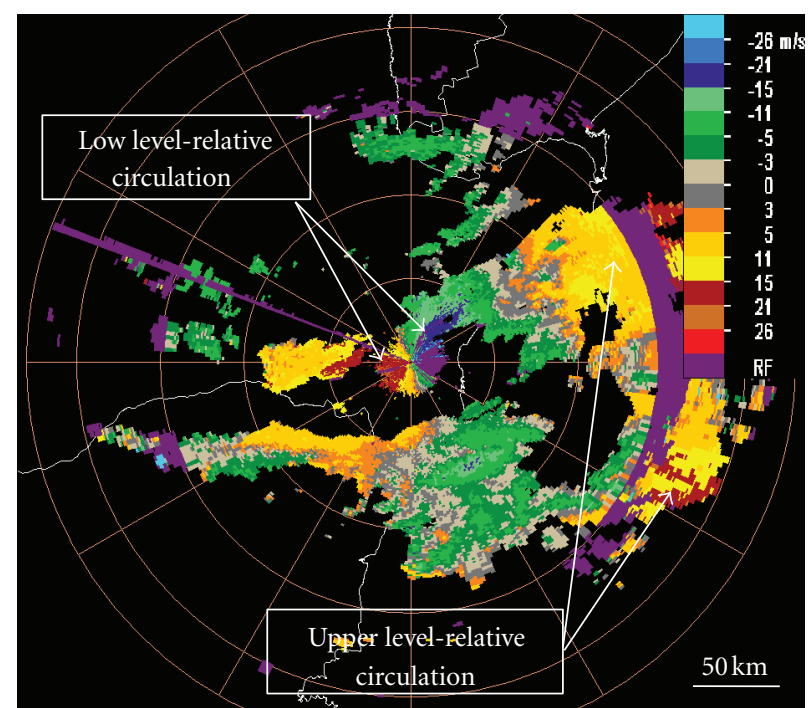

(b)

Figure 20: August 11, 2003, Doppler relative velocities, at 1432 UTC (a) and 1712 UTC (b) at 1.5-degree elevation.

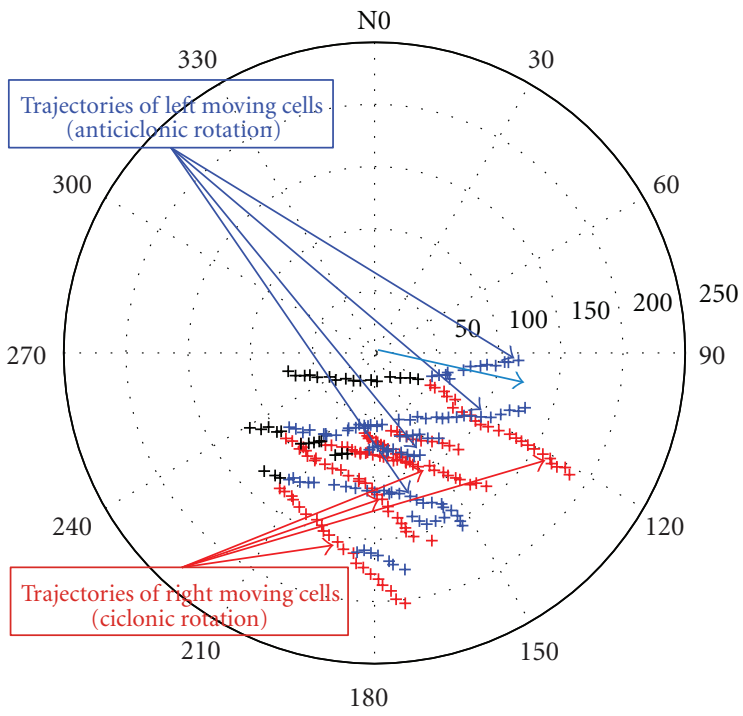

(a)

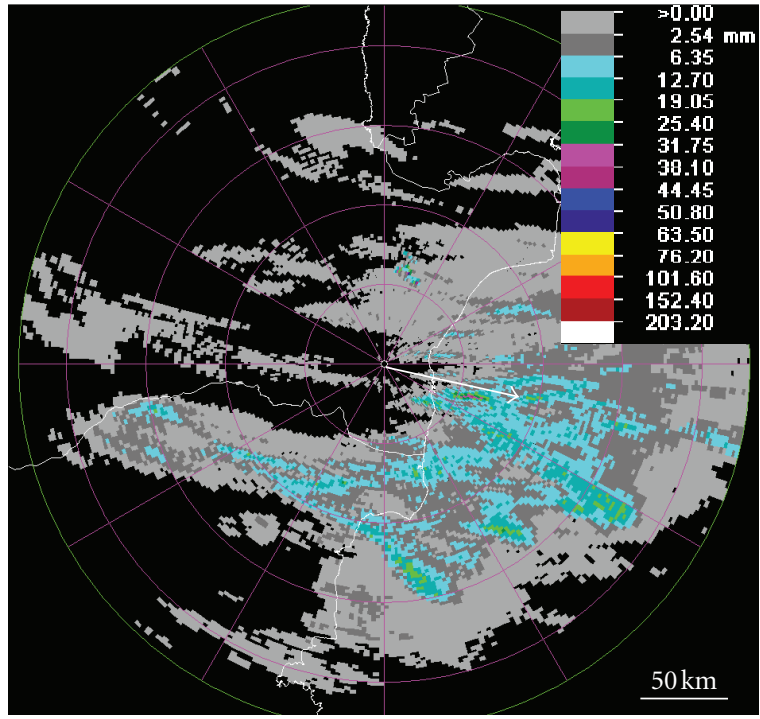

(b)

Figure 21: August 11, 2003, (a) the convective cells distribution, between 1126 UTC and 1925 UTC, using the Medgidia Doppler radar. The center of the image marks both the radar site and the origin of coordinates. The vector represents the mean shear for 1500-6700 m. Red stands for cyclonic rotation, blue for anticyclonic, and black signifies cells before split. The distance is measured in km. (b) Accumulated precipitation in mm, between 1547 UTC and 1847 UTC.

There is also rotation with values of shear around $0.04 \mathrm{~s}^{-1}$. In a first approximation, the vorticities of the vertical wind profile are comparable with those of the mesocyclone.

Trajectories of convective cells resulted from the split, present symmetry to the mean shear on the $1800-6000 \mathrm{~m}$ layer, with cells characterized by cyclonic rotation to the left of the vector and cells with anticyclonic rotation to the right (Figure 13(a)).

The evolution of these cells shows that the intensity of cyclonic rotation is greater than that of anticyclonic rotation.
The precipitation distribution function, by shear in the 1800-5000 m layer is represented in Figures 13(b), 13(c), and 13(d). Grouping in three-hour intervals was made in order to highlight the symmetry of precipitation distributions from shear vector. Large amounts were recorded at the intersection of several trajectories caused by several splits and also to the right of shear.

3.3. The Third Studied Case, August 11, 2003. In this case, starting at 1300 UTC, in SE Romania and NE Bulgaria, during 


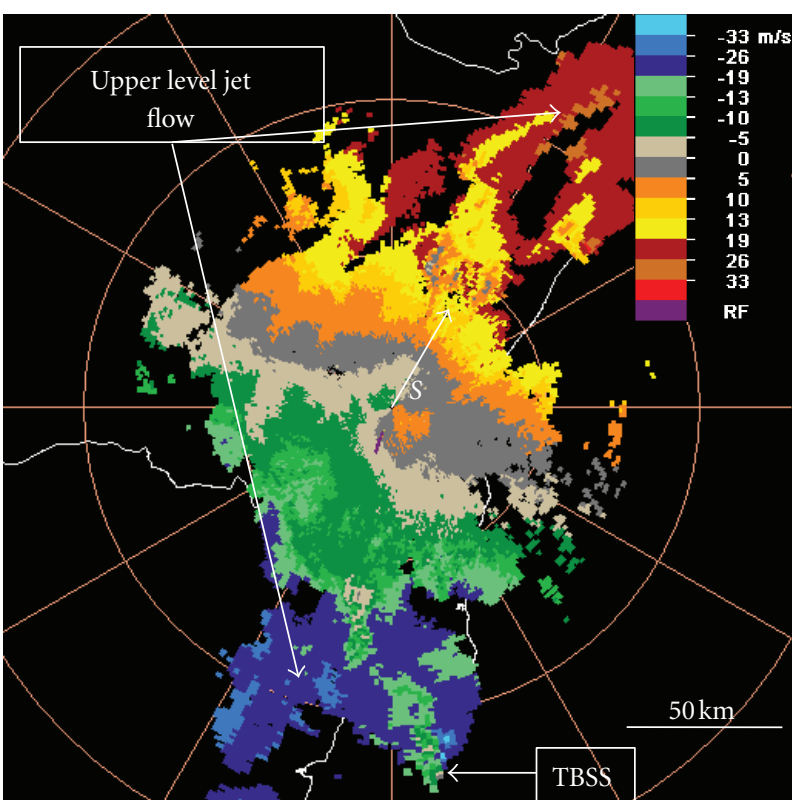

(a)

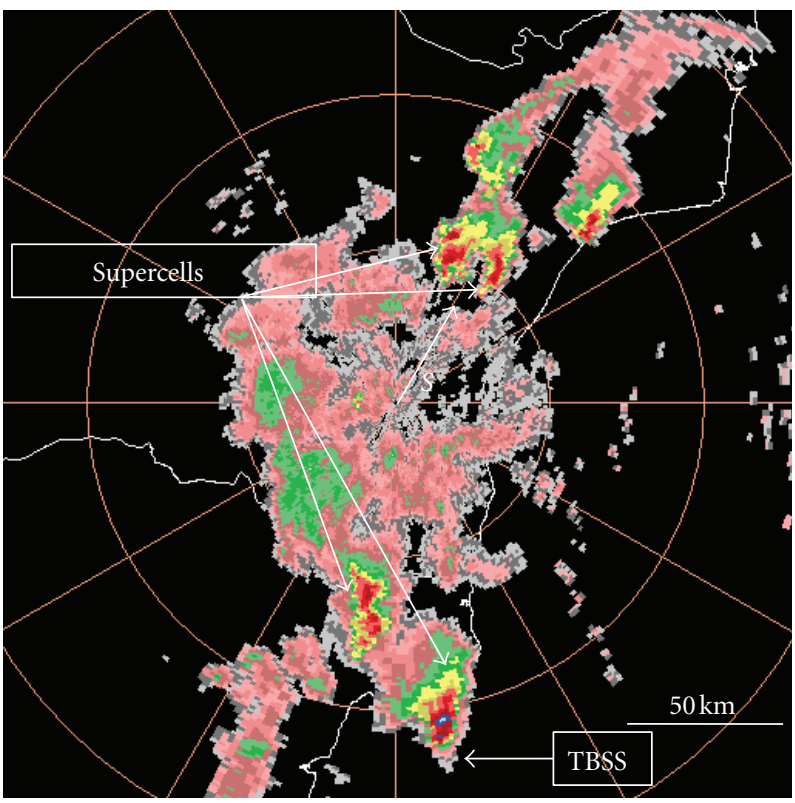

(c)

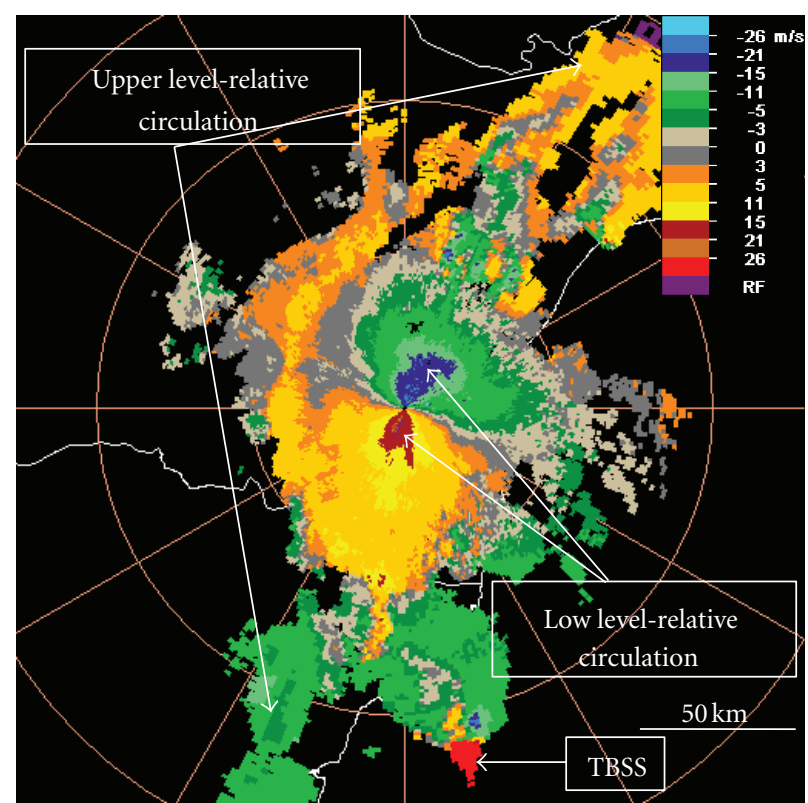

(b)

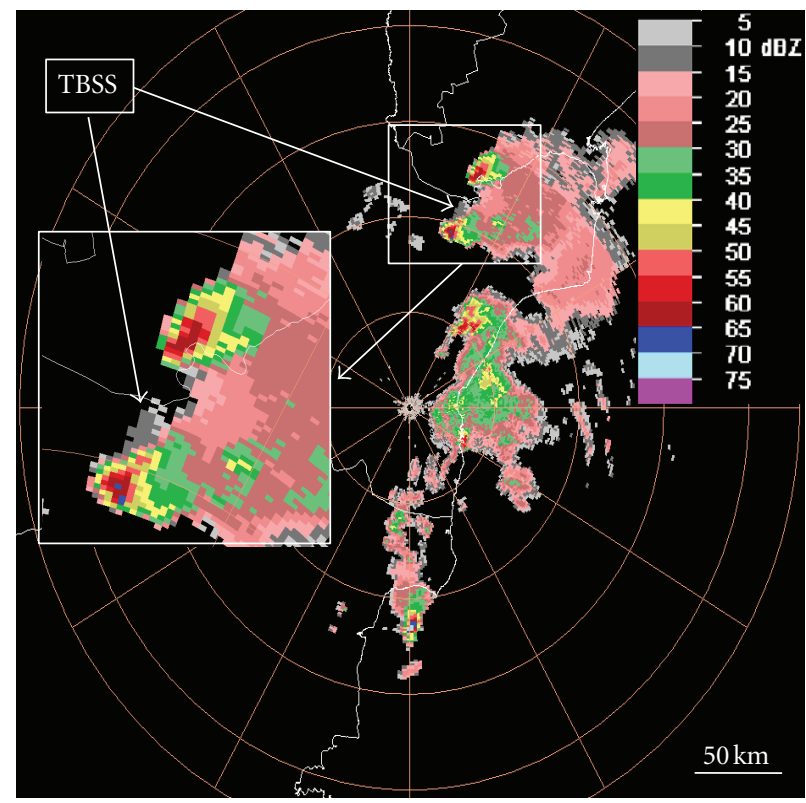

(d)

Figure 22: September 27, 2004: (a) Doppler velocities at 1347 UTC, at 3.4-degree elevation; (b) Doppler relative velocities at 1347 UTC, at 3.4-degree elevation; (c) reflectivity at 1347 UTC, at 1.5-degree elevation.

the fast evolution of a trough which moved from $\mathrm{W}$ to $\mathrm{E}$, convective cells have developed with supercell characteristics, visible in the radar-swept area.

About this event it can be readily said that, depending on the wind distribution, vertical shear, and time of day, two dynamic behaviors are distinguishable. As such, in the interval 0400 UTC-1115 UTC, the vertical velocity profile is characterized by a moderate mesoscale flow above $1500 \mathrm{~m}$ (Figure 14(a)). The radar reflectivity at 1.5-degree elevation is in echoes with a strip form, perhaps associated with conditional symmetric instability $[41,42]$ or with an internalgravitational wave [18] (Figure 14(b)). Here, no splitting process occurred.

As it can be seen in Figure 15, wind velocities have a maximum at $20 \mathrm{~m} \mathrm{~s}^{-1}$ at $2000 \mathrm{~m}$. The vorticity distribution, shown in Figure 16, has a pronounced maximum of $0.04 \mathrm{~s}^{-1}$ at $1000 \mathrm{~m}$.

Between 1328 UTC and 1432 UTC, the mesoscale dynamic state changes, a ULJ being present in the high troposphere, that can be seen in the vertical profile of 


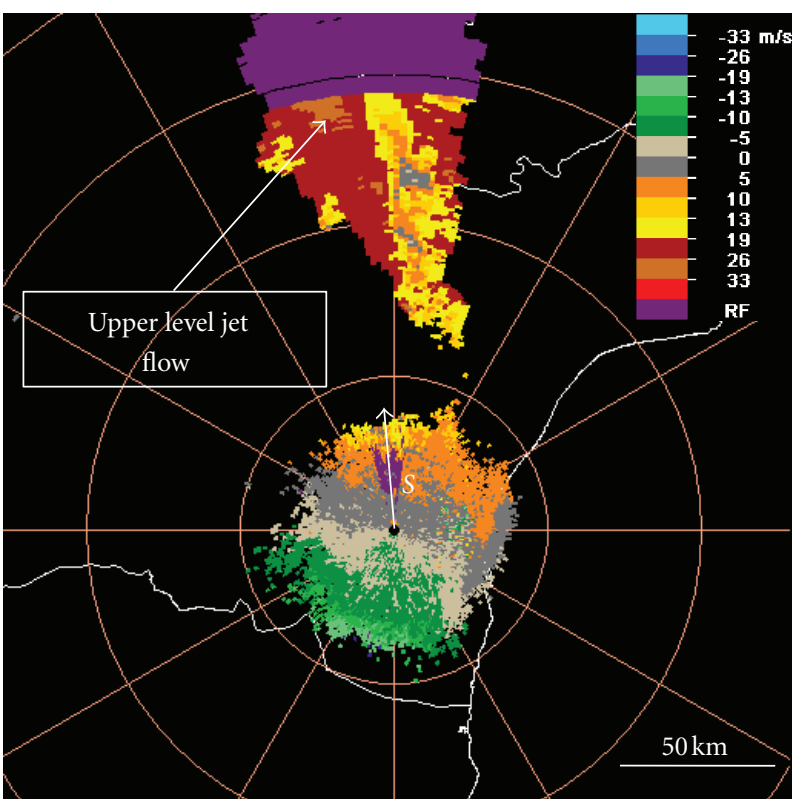

(a)

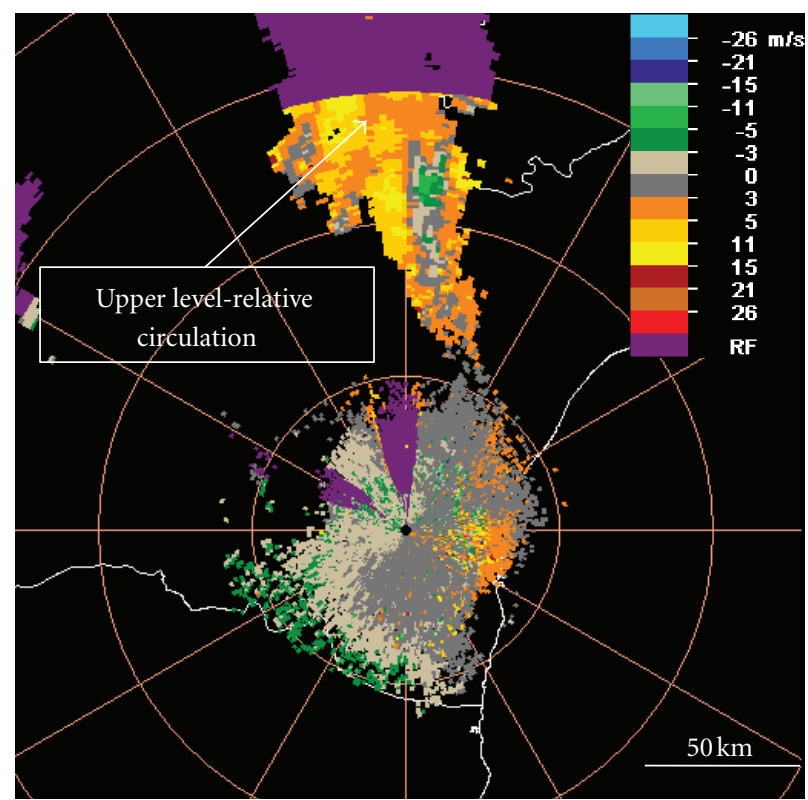

(b)

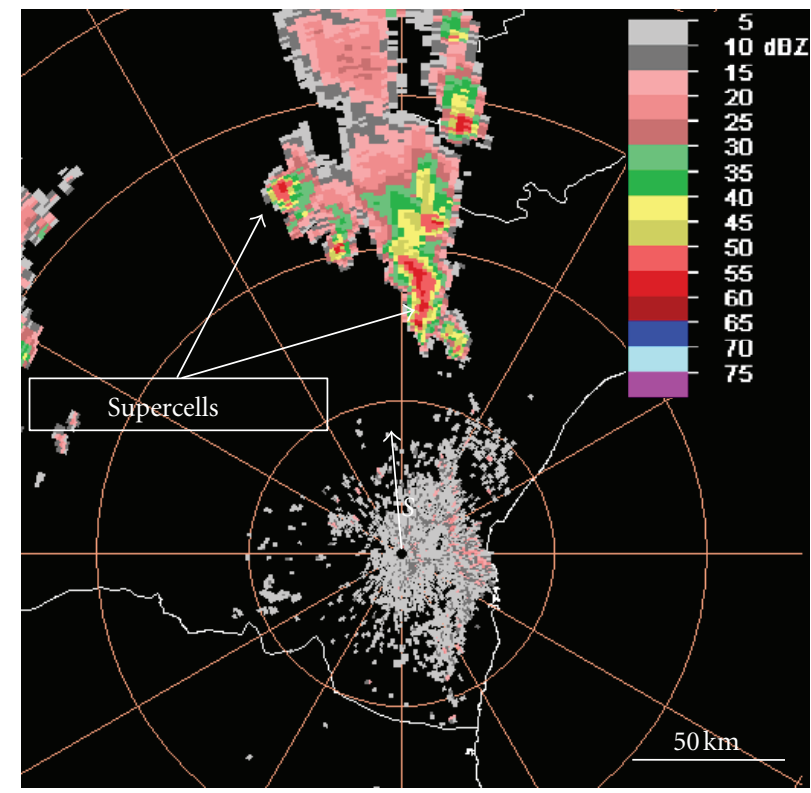

(c)

FIgURE 23: June 23, 2009: (a) Doppler velocities, at 1004 UTC at 3.4-degree elevation; (b) Doppler relative velocities, at 1004 UTC at 2.4-degree elevation; (c) reflectivity, at 1004 UTC at 1.5-degree elevation.

horizontal wind (Figure 17(a)). Between 304 and $1500 \mathrm{~m}$, neither the measurements of wind nor the VAD Wind Profile are reliable. Here, the influence of convective phenomena that can generate gust fronts is present. In Figure 18 the presence of the tropospheric jet is shown by velocities of 37 to $40 \mathrm{~m} \mathrm{~s}^{-1}$ at $6700 \mathrm{~m}$. Due to the tropospheric jet, the reflectivity field has changed, emphasizing now the splitting process both in radar reflectivities and Doppler relative velocities (Figures 17(b) and $17(\mathrm{c}))$.

Mesocyclone vorticities associated with convective cells that split are represented by parallel lines with the vertical axes (Figure 19). Note that most of vorticity values lie between $-0.001 \mathrm{~s}^{-1}$ and $-0.009 \mathrm{~s}^{-1}$, and between $0.001 \mathrm{~s}^{-1}$ and $0.009 \mathrm{~s}^{-1}$. The maximum vorticity here had a value around $0.011 \mathrm{~s}^{-1}$.

The Doppler relative velocities to the elevation of 1.5 degrees, Figures 20(a) and 20(b), show a relative jet in the low levels, whose speed is up to $23 \mathrm{~ms}^{-1}$ at $500 \mathrm{~m}$, while the relative flow at higher levels (above $6000 \mathrm{~m}$ ) gets to $18 \mathrm{~m} \mathrm{~s}^{-1}$. Spatial distribution of convective cell trajectories before and after splitting is shown in Figure 21(a). There is overlapping of the mean tropospheric shear vector on the $1500-6700 \mathrm{~m}$ 
layer. Symmetric trajectories to the mean shear are seen. In the precipitation field (Figure 21(b)), cells having higher water amounts are to the right side of the mean shear.

3.4. Other Cases (September 27, 2004; June 23, 2009). In the first case, a quasi-stationary trough of a big amplitude was present to the west of Romania. The first severe convective cells were seen by the radar at 1020 UTC in Bulgaria and were advected in Romania by the tropospheric circulation. The convective cells which later split were initiated nearby the radar site at 1220 UTC. In this case, the convective cells with anticyclonic rotation had a bigger life time and a greater severity as well.

In the second case, the mesosynoptic configuration was modulated by the cyclone west of Romania. The circulation due to this cyclone was southern over the south east of Romania in the boundary layer as well as at higher altitude. In the first part of the day, the Doppler radar caught a mesoconvective system with supercells. After the convective system dissipated, other new convective cells have been initiated and split; the most severe ones of them have cyclonic rotation.

As in the cases above, for these two other cases the main feature associated with the mesoscale configuration was the ULJ, whose speed exceeded $33 \mathrm{~m} \mathrm{~s}^{-1}$. In the first case (September 27, 2004), intense flow is visible at lower levels in the field of Doppler relative velocity, and in upper layers at approximately $11-15 \mathrm{~m} \mathrm{~s}^{-1}$, as visible in Figure 22(b).

The convective cells in Romania that evolved to the left of tropospheric shear were associated with nonnegligible probability of hail as indicated by the presence of ThreeBody Scatter Spike (Figure 22(d)). Cyclonic shear at low levels (Figure 22(a)) can be a direct indication of the severity of convective cells that propagate to the left of the shear vector. The cells in Bulgaria show strong propagation to the right of the tropospheric shear and also showing the Three-Body Scatter Spike (Figure 22(c)). For these, the splitting process was not seen. In the second case (June 23, 2009), intense flow is not present at lower levels in the field of Doppler velocity relatively, but a relatively high speed of flow of about $15 \mathrm{~m} \mathrm{~s}^{-1}$ is seen at upper levels (Figure 23(b)). The radar reflectivity field at 1.5-degree elevation (Figures 22(c) and 23(c)) highlights the splitting process; the secondary cells evolve to the right (cyclonic rotation) and to the left (anticyclone rotation) of the shear vector $S$ in the 1800-6000 m layer.

\section{Conclusions}

This study shows the splitting process in SE Romania, linked to convective developments which can be seen using the Sband Doppler radar. This process is important as a dynamic one, because it can modulate the energy transfer between the synoptic scale and the mesoscale. The main mesosynoptic conditions associated with the generation of this dynamic process can be distinguished, and also its evolution. Information about all of these can be used as an additional tool in nowcasting.
From the analysis of convective cells resulted from the split it can be said that the splitting process of convective cells observed in radar fields indicates a corresponding severe weather event. As a fundamental condition, splitting of convective cells occurred when an upper level jet $\left(30 \mathrm{~m} \mathrm{~s}^{-1}-40 \mathrm{~m} \mathrm{~s}^{-1}\right)$ was detected in the high troposphere (above $6000 \mathrm{~m}$ ). In the first stages of the convective cells, the presence of the jet stream in the upper troposphere and especially its vertical extent lead them to be strongly advected by the flow. Also, the presence at lower levels of a directional variation in the horizontal wind vector leads to a stronger relative flow. In the case of a tropospheric configuration that favours the splitting process, the lower relative flow has a high intensity and is opposite to the upper relative flow; this configuration is seen in the relative Doppler velocities field at different elevations. In all the three detailed cases, below $1800 \mathrm{~m}$ the horizontal wind vector had a rotation associated to the asymmetry of the splitting process, and also to the strong relative flow between 100 and $1000 \mathrm{~m}$, providing a powerful moisture flow through updraft and strong vorticity advection.

All the analysed cases have shown the independence of the splitting process to the atmosphere circulation. This is characteristic to baroclinic waves with a west-to-east evolution, and also to cyclones near Romania: north-west circulation for May 1-28, 2008, south-east circulation for June 2-25, 2009, west circulation for August 3-11, 2003, south-south-east circulation for September 27, 2004, and south circulation for June 23, 2009.

The largest amounts of precipitation are related to cell cross-trajectories associated with the splitting process and lie to the right of shear in 1800-6000 m layer (Figures 6, 13, and 21). The splitting process may lead to a mesoscale convective system. If this happens the secondary cells interact constructively afterwards; this will happen to the right side of the mean tropospheric shear.

The local maxima of vertical vorticity (Figures 9, 13, and 21 ) are most positive (to the right side of the 0,0 coordinate). Keeping the same sign of horizontal vorticity is essential in formation of cyclonic and anticyclonic vortices, confirmed by Figure 1. The magnitude of the horizontal vorticity associated with vertical wind profiles and that of vertical vorticity for cyclonic and anticyclonic rotation are comparable; the majority of values is lying in the $0.001 \mathrm{~s}^{-1}-0.009 \mathrm{~s}^{-1}$ interval (in a first approximation, these magnitudes verify the dynamic process associated to the formation of cyclonic and anticyclonic vortices).

Both the June 25, 2009 and in the September 27, 2004 cases highlight the TBSS associated with convective cells (anticyclonic rotation) with a motion to the left of the shear vector in the mean troposphere, which means that these cells have attributes that indicate the presence of severe hail. An explanation could be the fact that the convective cells with motion left to the mean shear are more isolated than those with motion to the right of it. The former cells are moving to the zone where the values of geopotential and temperature are falling. Here, the thermal gradient is perpendicular to 
the shear vector (thermal wind relation), something that can accelerate the increase in thermodynamic instability.

To have a good image of the splitting process, in the next studies observational data from meteorological stations and soundings would have to be used.

\section{References}

[1] A. Stan-Sion and C. Soci, "Supercell environment in Southeastern Romania," in Proceedings of the 5th Annual Meeting of the European Meteorological Society (EMS '05), 7th European Conference on Applications of Meteorology (ECAM '05), pp. 12-16, Utrecht, The Netherland, September 2005.

[2] A. Stan-Sion and B. Antonescu, "Mesocyclones in Romania-characteristics and environments," in Proceedings of the 23rd AMS Conference on Severe Local Storms (SLS '06), Louis, Mo, USA, November 2006.

[3] A. Bell, D. Carbunaru, B. Antonescu, and S. Burcea, "The Black Sea influence in convective storms initiation in South Eastern Romania," in Proceedings of the 34th AMS Conference on Radar Meteorology, Williamsburg, Va, USA, October 2009.

[4] A. Bell, "Mesoscale environment for tornadic supercells in SE Romania," in Proceedings of the 6th European Conference on Radar in Meteorology and Hydrology: Advances in Radar Technology, Sibiu, Romania, September 2010.

[5] B. Antonescu, D. Carbunaru, M. Sasu, S. Burcea, and A. Bell, "A climatology of supercells in Romania," in Proceedings of the 6th European Conference on Radar in Meteorology and Hydrology: Advances in Radar Technology, Sibiu, Romania, September 2010.

[6] C. A. Doswell III, On the Use of Hodographs-Vertical Wind Profile Information in Severe Storms Forecasting, U. S. Dept. Of Commerce/NOAA, National Severe Storms Laboratory and National Weather Service, Southern Region, Fort Worth, Tex, USA, 1988.

[7] M. J. Bunkers, "Vertical wind shear associated with left-moving supercells," Weather and Forecasting, vol. 17, no. 4, pp. 845-855, 2002.

[8] R. Rotunno, "On the evolution of thunderstorm rotation," Monthly Weather Review, vol. 109, pp. 577-586, 1981.

[9] R. Rotunno and J. B. Klemp, “The influence of shear-induced pressure gradient on thunderstorm motion," Monthly Weather Review, vol. 110, no. 2, pp. 136-151, 1982.

[10] E. A. Brandes, "Vertical vorticity generation and mesocyclone sustenance in tornadic thunderstorms: the observational evidence," Monthly Weather Review, vol. 112, no. 11, pp. 2253-2269, 1984.

[11] R. Davies-Jones, "Streamwise vorticity: the origin of updraft rotation in supercell storms," Journal of the Atmospheric Sciences, vol. 41, no. 20, pp. 2991-3006, 1984.

[12] J. B. Klemp, "Dynamic of tornadic thunderstorms," Annual Review of Fluid Mechanics, vol. 19, pp. 369-402, 1987.

[13] R. Davies-Jones, "Linear and nonlinear propagation of supercell storms," Journal of the Atmospheric Sciences, vol. 59, no. 22, pp. 3178-3205, 2002.

[14] R. P. Davies-Jones, "Reply to comment on Linear and nonlinear propagation of supercell storms," Journal of the Atmospheric Sciences, vol. 60, pp. 2420-2426, 2003.

[15] R. Rotunno and M. L. Weisman, "Comment on Linear and nonlinear propagation of supercell storms," Journal of the Atmospheric Sciences, vol. 60, pp. 2413-2419, 2003.
[16] J. M. L. Dahl, Supercells-Their Dynamics and Prediction, Free University of Berlin, Institute of Meteorology, Department of Theoretical Meteorology, 2006.

[17] Y.-L. Lin, Mesoscale Dynamics, Cambridge University Press, 2007.

[18] P. Markowski and Y. Richardson, Mesoscale Meteorology in Midlatitudes, Royal Meteorological Society, 2010.

[19] J. B. Klemp and R. B. Wilhelmson, "Simulation of right- and leftmoving storms produced through storm splitting," Journal of the Atmospheric Sciences, vol. 35, pp. 1097-1110, 1978.

[20] M. L. Weisman and J. B. Klemp, "The dependence of numerically simulated convective storms on vertical wind shear and buoyancy," Monthly Weather Review, vol. 110, no. 6, pp. 504-520, 1982.

[21] M. L. Weisman and J. B. Klemp, “The structure and classification of numerically simulated convective storms in directionally varying wind shears," Monthly Weather Review, vol. 112, no. 12, pp. 2479-2498, 1984.

[22] L. D. Grasso, "The dissipation of a left-moving cell in a severe storm environment," Monthly Weather Review, vol. 128, no. 8, pp. 2797-2815, 2000.

[23] D. L. Andra Jr., "Observation of an anticyclonically rotating severe storm," in Proceedings of the 17th Conference onn Severe Local Storms, pp. 186-190, American Meteorological Society, St. Louis, Mo, USA, 1993.

[24] R. P. Kleya, "A radar and synoptic scale analysis of a splitting thunderstorm over north-central Texas on November 10, 1992," in Proceedings of the 17th Conference On Severe Local Storms, pp. 211-213, American Meteorological Society, St. Louis, Mo, USA, 1993.

[25] F. H. Glass and S. C. Truett, "Observation of a splitting severe thunderstorm exhibiting both supercellular and multicellular traits," in Proceedings of the 17th Conference On Severe Local Storms, pp. 224-228, American Meteorological Society, St. Louis, Mo, USA, 1993.

[26] R. A. Brown and R. J. Meitín, "Evolution and morphology of two splitting thunderstorms with dominant left-moving members," Monthly Weather Review, vol. 122, pp. 2052-2067, 1994.

[27] G.W. Carbin, "Analysis of a splitting severe thunderstorm using the WSR-88D," NWS Eastern Region WSR-88D Operational Note 08, National Weather Service, Eastern Region Headquarters, Bohemia, NY, USA, 1997.

[28] L. D. Grasso and E. R. Hilgendorf, "Observations of a severe left moving thunderstorm," Weather and Forecasting, vol. 16, no. 4, pp. 500-511, 2001.

[29] J. P. Monteverdi, W. Blier, G. Stumpf, W. Pi, and K. Anderson, "First WSR-88D documentation of an anticyclonic supercell with anticyclonic tornadoes: the Sunnyvale-Los Altos, California, tornadoes of 4 May 1998," Monthly Weather Review, vol. 129, no. 11, pp. 2805-2814, 2001.

[30] J. F. Dostalek, J. F. Weaver, and G. L. Phillips, "Aspects of a tornadic left-moving thunderstorm of 25 may 1999," Weather and Forecasting, vol. 19, no. 3, pp. 614-626, 2004.

[31] D. T. Lindsey and M. J. Bunkers, "Observations of a severe, leftmoving supercell on 4 May 2003," Weather and Forecasting, vol. 20, no. 1, pp. 15-22, 2005.

[32] R. Edwards and S. J. Hodanish, "Photographic documentation and environmental analysis of an intense, anticyclonic supercell on the Colorado plains," Monthly Weather Review, vol. 134, no. 12, pp. 3753-3763, 2006. 
[33] E. N. Rasmussen and J. M. Straka, "Variations in supercell morphology. Part I: observations of the role of upper-level storm-relative flow," Monthly Weather Review, vol. 126, no. 9, pp. 2406-2421, 1998.

[34] National Oceanic Atmospheric Administration (NOAA), http://www.wdtb.noaa.gov/courses/dloc/index.html.

[35] R. M. Lhermitte and D. Atlas, "Precipitation motion by pulse Doppler radar," in Proceedings of the 9th Conference on Radar Meteorology, pp. 218-223, American Meteorological Society, 1961.

[36] K. A. Browning and R. Wexler, "The determination of kinematic properties of a wind field using Doppler radar," Journal of Applied Meteorology, vol. 7, pp. 105-113, 1968.

[37] R. A. Fulton, P. Breidenbach, D. J. Sco, D. A. Miler, and T. O'Bannon, “The WSR-98D rainfall algorithm," Weather Forecast, vol. 13, pp. 337-395, 1988.

[38] D. S. Zrnic, “Three-body scattering produces precipitation signature of special diagnostic value," Radio Science, vol. 22, no. 1, pp. 76-86, 1987.

[39] J. B. Wilson and D. Reum, "The flare echo: reflectivity and velocity signature," Journal of Atmospheric and Oceanic Technology, vol. 5, pp. 197-205, 1988.

[40] L. R. Lemon, "The Radar "Three-Body Scatter Spike": an operational large-hail signature," Weather and Forecasting, vol. 13, pp. 327-340, 1988.

[41] D. A. Bennetts and J. C. Sharp, "The relevance of conditional symmetric instability to the prediction of mesoscale frontal rainbands," Quarterly Journal Royal Meteorological Society, vol. 108, no. 457, pp. 595-602, 1982.

[42] D. M. Schultz and J. A. Knox, "Banded convection caused by frontogenesis in a conditionaly, symmetrically, and inertialy unstable environment," Monthly Weather Review, vol. 135, pp. 2095-2110, 2007. 

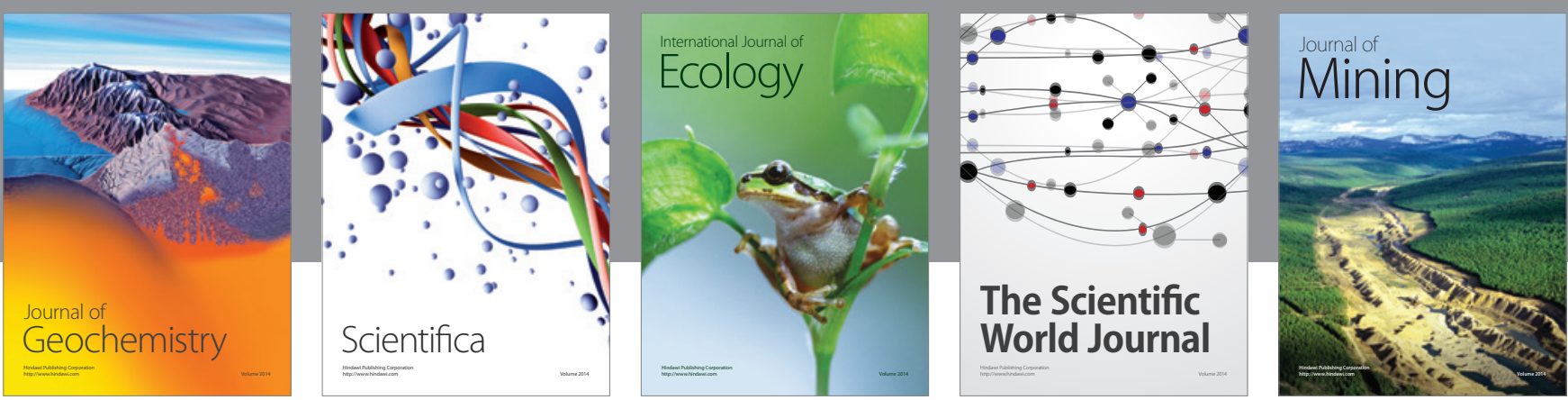

The Scientific World Journal
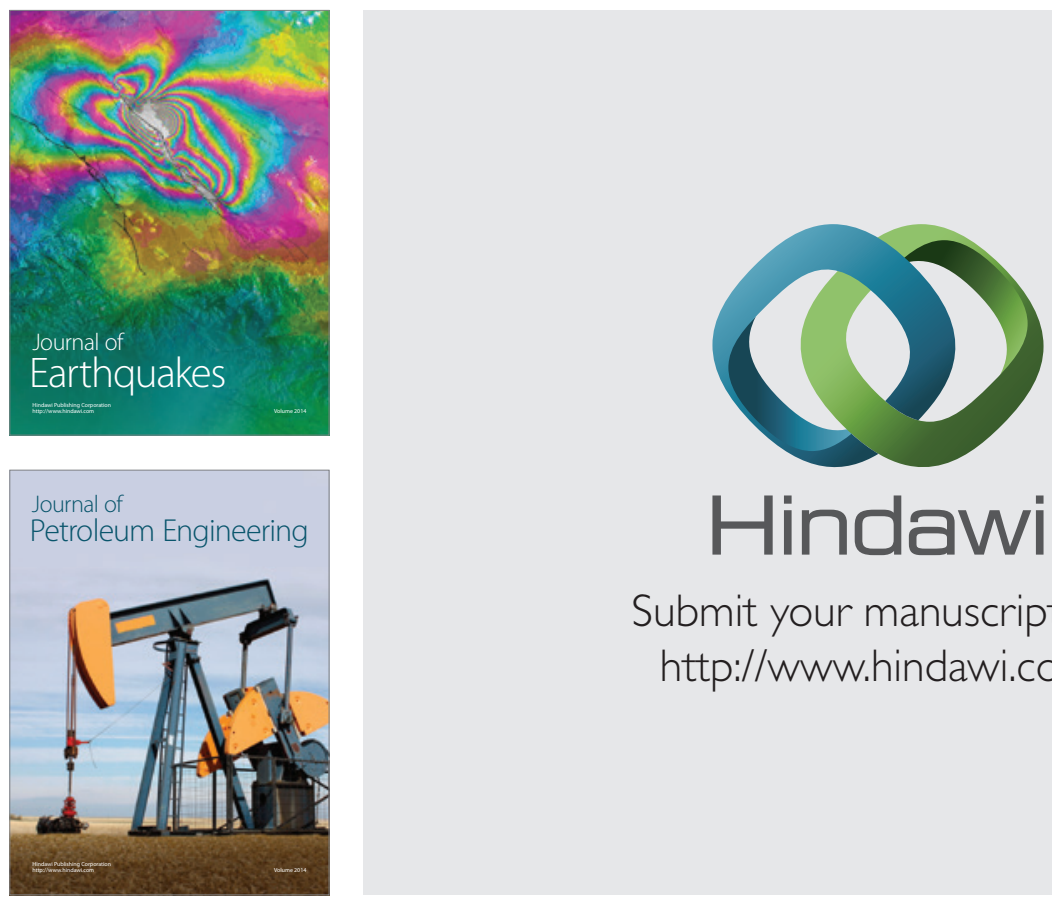

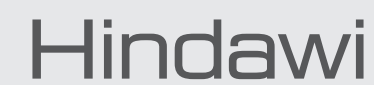

Submit your manuscripts at

http://www.hindawi.com
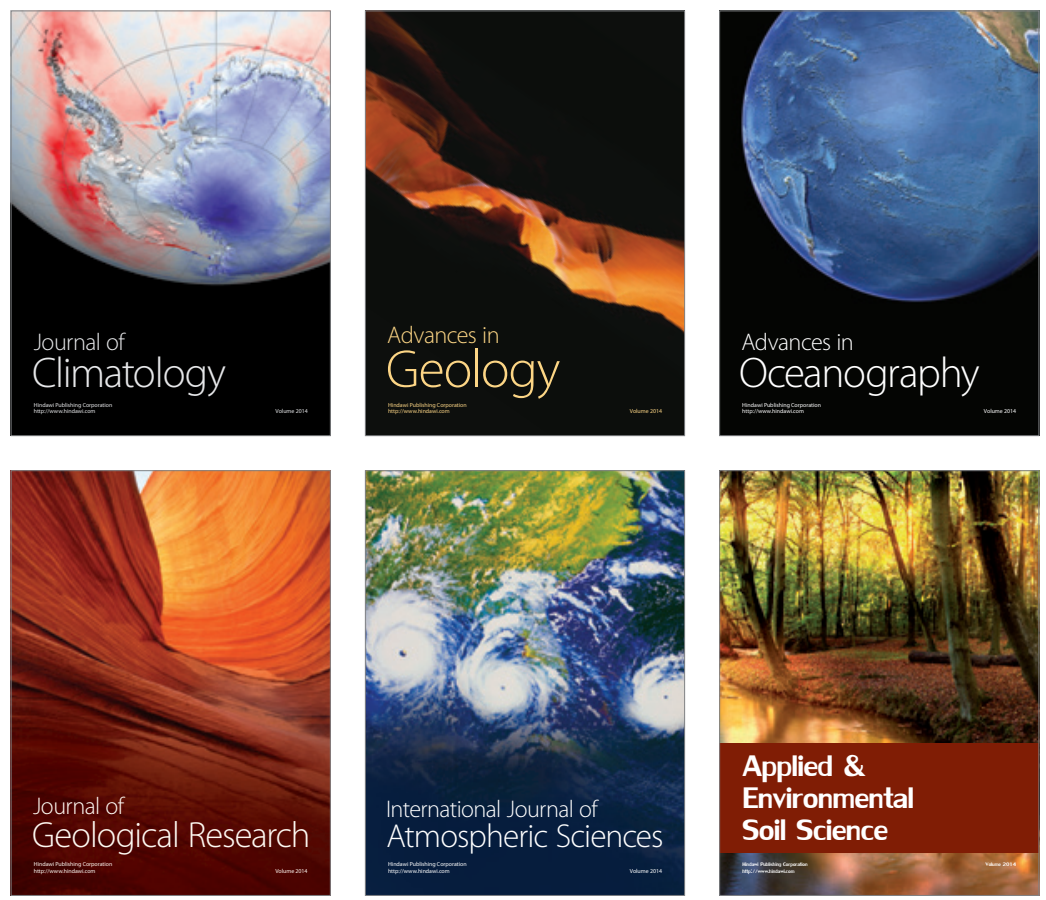
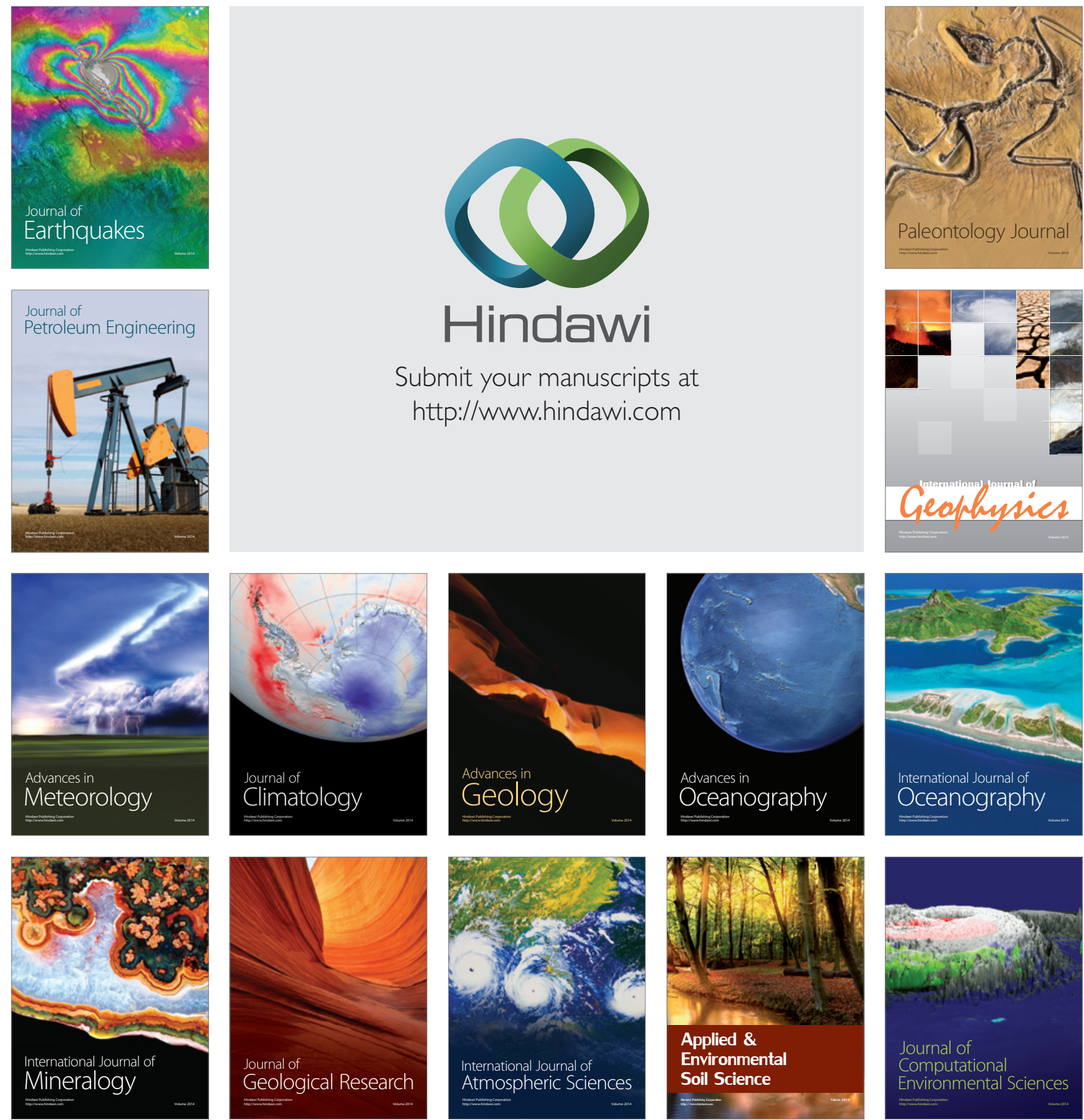